\title{
lodine intake as a risk factor for thyroid cancer: a comprehensive review of animal and human studies
}

\author{
Michael B. Zimmermann ${ }^{1 *}$ and Valeria Galetti ${ }^{2}$
}

\begin{abstract}
Thyroid cancer (TC) is the most common endocrine malignancy and in most countries, incidence rates are increasing. Although differences in population iodine intake are a determinant of benign thyroid disorders, the role of iodine intake in TC remains uncertain. We review the evidence linking iodine intake and TC from animal studies, ecological studies of iodine intake and differentiated and undifferentiated TC, iodine intake and mortality from TC and occult TC at autopsy, as well as the case-control and cohort studies of TC and intake of seafood and milk products. We perform a new meta-analysis of pooled measures of effect from case-control studies of total iodine intake and TC. Finally, we examine the post-Chernobyl studies linking iodine status and risk of TC after radiation exposure. The available evidence suggests iodine deficiency is a risk factor for TC, particularly for follicular TC and possibly, for anaplastic TC. This conclusion is based on: a) consistent data showing an increase in TC (mainly follicular) in iodine deficient animals; b) a plausible mechanism (chronic TSH stimulation induced by iodine deficiency); c) consistent data from before and after studies of iodine prophylaxis showing a decrease in follicular TC and anaplastic TC; d) the indirect association between changes in iodine intake and TC mortality in the decade from 2000 to 2010; e) the autopsy studies of occult TC showing higher microcarcinoma rates with lower iodine intakes; and f) the case control studies suggesting lower risk of TC with higher total iodine intakes.
\end{abstract}

Keywords: lodine deficiency, lodine excess, lodine status, lodized salt, lodine supplement, Urinary iodine, Goiter, Nodule, Thyroid cancer

\section{Introduction}

Thyroid cancer (TC) is the most common endocrine malignancy and in most countries, incidence rates have been steadily increasing over the past few decades, particularly in women. In 2012, the age standardized (world population) incidence rate was 6.1/100,000 women and $1.9 / 100,000$ men [1]. Comparing populations around the world, there is a greater than ten-fold difference in incidence; high incidence areas (incidence rates greater than 10/100,000 women) are Japan and the Pacific Islands, Italy and several countries in the Americas. Incidence rates in developed countries are more than twofold higher than in developing countries (in women, 11.1/

\footnotetext{
* Correspondence: michael.zimmermann@hest.ethz.ch

'Laboratory of Human Nutrition, Department of Health Sciences and Technology, ETH Zürich, Schmelzbergstrasse 7, LFV D21, CH-8092 Zürich, Switzerland

Full list of author information is available at the end of the article
}

$100,000$ versus $4.7 / 100,000)$ [1]. If recent trends continue, thyroid cancer will be the fourth most common cancer in the U.S. by 2030 [2]. Papillary thyroid cancer (PTC) is by far the most prevalent subtype, in most countries accounting for greater than $80 \%$ of thyroid cancer, but anaplastic thyroid cancer (ATC), because of its poor prognosis, accounts for a large portion of the mortality. Increased screening and diagnostic testing is likely the major, but may not be the only, contributor to the rising incidence of thyroid cancer [3-7]. Suspected risk factors include radiation exposure during childhood (whether from nuclear accidents, natural radiation or medical imaging) [8-10], obesity and the metabolic syndrome [11, 12], environmental pollutants [13, 14], a family history of thyroid cancer or thyroid disorders [15], and possibly, iodine intake.

It is clear that variations in population iodine intake are a primary determinant of benign thyroid disorders,

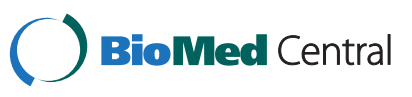

(C) 2015 Zimmermann and Galetti. This is an Open Access article distributed under the terms of the Creative Commons Attribution License (http://creativecommons.org/licenses/by/4.0), which permits unrestricted use, distribution, and reproduction in any medium, provided the original work is properly credited. The Creative Commons Public Domain Dedication waiver (http://creativecommons.org/publicdomain/zero/1.0/) applies to the data made available in this article, unless otherwise stated. 
such as goiter, nodules, and hyper- and hypothyroidism [16]. In contrast, the role of iodine intake in thyroid cancer remains uncertain, despite decades of study and debate. At the 1927 International Conference on Goiter, the eminent pathologist Carl Wegelin argued that thyroid cancer was more common in areas of endemic goiter, with frequency at autopsy varying from 1.04 per cent in central Switzerland, an endemic goiter region, to 0.09 per cent in Berlin, a non-endemic region [17]. He predicted a drop in incidence of thyroid cancer as endemic goiter disappeared due to iodized salt, with a lag time of 30 to 40 years. Iodized salt was introduced into a handful of countries in the 1920s and then increasingly since the 1960s; in 2015, around 100 countries have national iodized salt programs [18]. Although there has been a decrease in the prevalence of ATC in many of these countries, at the same time the incidence of PTC has increased, particularly since the 1980 s, as discussed below. Because of this temporal pattern, several authors have suggested increasing iodine intakes are contributing to the increase in PTC, while others disagree.

The prevalence of goiter and thyroid nodules is higher in iodine deficient populations [19] and goiter and nodularity, in many cases, precede the development of thyroid cancer [20]. In animal studies, chronic thyroid-stimulating hormone (TSH) stimulation produces thyroid tumors, and because an increase in TSH is an adaptation to iodine deficiency, one might expect this could be the mechanism for an increased incidence of thyroid cancer in iodine deficient populations [21]. However, mean TSH may be actually lower in mildly iodine deficient populations than in populations with higher iodine intakes [16], and the highest incidence rates for thyroid cancer are in Japan, where iodine intake is high [22]. On the other hand, mortality from thyroid cancer tends to be higher in regions of endemic goiter because of more frequent advanced tumor stages at diagnosis and an increased ratio of more aggressive subtypes. Clearly, the links between iodine intake and thyroid cancer are complex, and are discussed in detail in this review.

Recommended daily iodine intakes from WHO/UNICEF/ ICCIDD are $90 \mu \mathrm{g}$ for infants and young children (0-59 months), $120 \mu \mathrm{g}$ for children $6-12$ years, $150 \mu \mathrm{g}$ for adolescents and adults, and $250 \mu \mathrm{g}$ for pregnant and lactating women [23]. To assess iodine intakes and status of populations, WHO recommend the use of spot urine collections to measure the urinary iodine concentration (UIC), expressed as the median in $\mu \mathrm{g} / \mathrm{L}$. National UIC surveys are often done in school-aged children because they are easy to reach through school-based surveys and their iodine status can be used as a proxy for the non-pregnant adult population [23]. The median UIC is an excellent biomarker of recent exposure to iodine in populations, because it reflects intake from all dietary sources [24]. The median UIC criteria for iodine nutrition are shown in Table 1 [23]. These WHO criteria are used throughout this review to describe iodine nutrition in populations as deficient, sufficient or excessive.

\section{Review}

Animal studies

Thyroid cancer in animals fed iodine deficient or iodine excessive diets

In female rats, provision of iodine deficient diets for 6 to 20 months increases serum TSH and causes thyroid tumors in $54-100 \%$ of animals, mainly follicular adenomas and follicular carcinomas [25-28]. Similar effects were observed in hamsters [29], where the malignancies reported were both follicular and papillary carcinomas. Correa and Welsh [30] fed rats $(n=30)$ for 9 months a diet containing excess iodine $(\approx 120 \mathrm{mg}$ of iodine per day) or a control diet. There was a $40 \%$ increase in thyroid weight, and histologic changes included enlarged follicles with increased colloid lined by flattened epithelia, but no thyroid tumors were found.

\section{Thyroid cancer in animals fed iodine deficient or iodine excessive diets and exposed to carcinogens}

Thyroid tumor-promoting effects of iodine deficiency and excess have also been investigated in two-stage models in rats given carcinogens, such as N-bis(2-hydroxypropyI)-nitrosamine (DHPN) or N-nitrosomethylurea (NMU), and provided iodine deficient or excessive diets [31-33]. In iodine deficient rats, administration of NMU induces thyroid cancer after a shorter latency period and at higher incidence and multiplicity when compared to rats only iodine deficient or to rats that received NMU but were iodine sufficient [31, 32]. Kanno et al. [33] examined the potential thyroid tumor-promoting effects of iodine deficiency and excess for 26 weeks in a 2-stage model in rats given DHPN or saline. In saline-treated rats, iodine deficiency or excess alone was not carcinogenic,

Table 1 Epidemiological criteria for assessment of iodine nutrition in populations based on median urinary iodine concentration [23, 24].

\begin{tabular}{lll}
\hline $\begin{array}{l}\text { Median } \\
\text { urinary iodine } \\
\text { concentration (UIC) }\end{array}$ & lodine intake & lodine nutrition \\
\hline$<20 \mu \mathrm{g} / \mathrm{L}$ & Insufficient & Severe iodine deficiency \\
$20-49 \mu \mathrm{g} / \mathrm{L}$ & Insufficient & Moderate iodine deficiency \\
$50-99 \mu \mathrm{g} / \mathrm{L}$ & Insufficient & Mild iodine deficiency \\
$100-299 \mu \mathrm{g} / \mathrm{L}$ & $\begin{array}{l}\text { Adequate or } \\
\text { more-than-adequate }\end{array}$ & $\begin{array}{l}\text { Sufficient } \\
\geq 300 \mu \mathrm{g} / \mathrm{L}\end{array}$ \\
& Excessive & $\begin{array}{l}\text { Risk of adverse health } \\
\text { consequences (iodine-induced } \\
\text { hyperthyroidism, autoimmune } \\
\end{array}$ \\
& & thyroid disease) \\
\hline
\end{tabular}


but in DHPN-treated rats, both iodine deficiency and excess increased thyroid follicular tumors, with iodine deficiency having a markedly stronger effect (Fig. 1a). In a similar 2-stage study that exposed rats to $\mathrm{N}$ nitrosobis(2-hydroxypropyl)amine (BHP) and an excessive iodine diet [34], the incidence of thyroid cancer was $29 \%$ in those fed the excessive iodine diet versus $33 \%$ in those fed the iodine sufficient diet. To study the effects of iodine deficiency early in life on subsequent susceptibility to thyroid carcinogens, an iodine-free diet was fed to lactating rats and their weaned offspring until postnatal week 7 , and then the offspring were exposed to DHPN [35], but this did not significantly increase thyroid tumors.

Boltze et al. [36] fed rats over a period of 110 weeks high $(\approx 10$ times normal), normal, and low $(\approx 0.1$ times normal) daily iodine intake and subjected them to single external radiation of 4 gray (Gy) or sham radiation. This study differed from the animal studies described above in that the induced iodine deficiency and excess were less severe and the experiments were done in younger rats. Iodine deficiency induced a doubling of serum TSH, while iodine excess had no effect on TSH. Alone, both iodine deficiency and excess increased the thyrocyte proliferation rate and induced thyroid adenomas, but induced no thyroid carcinomas. Combined with radiation, both iodine deficiency and iodine excess induced thyroid carcinomas (PTC and follicular thyroid cancer, FTC) in $50-80 \%$ of animals, while iodine sufficient animals did not develop thyroid carcinomas (Fig. 1b). These data suggest both long-term iodine deficiency and excess are insufficient to stimulate thyroid carcinogenesis, but both promote thyroid carcinogenesis induced by radiation.

\section{Conclusions}

Overall, these animal studies suggest that iodine deficiency acts primarily as a promoter rather than as an initiator of thyroid carcinogenesis, or as a weak complete carcinogen. Iodine excess appears not to be an initiator, but may be a weak promoter. The relevance of the thyroid tumors produced in these animal experiments to human lesions is uncertain: most of the studies induced profound iodine deficiency and excess more severe than found in human diets, and, in general, the follicular tumors show a pattern of morphology and behavior different from human thyroid cancers.
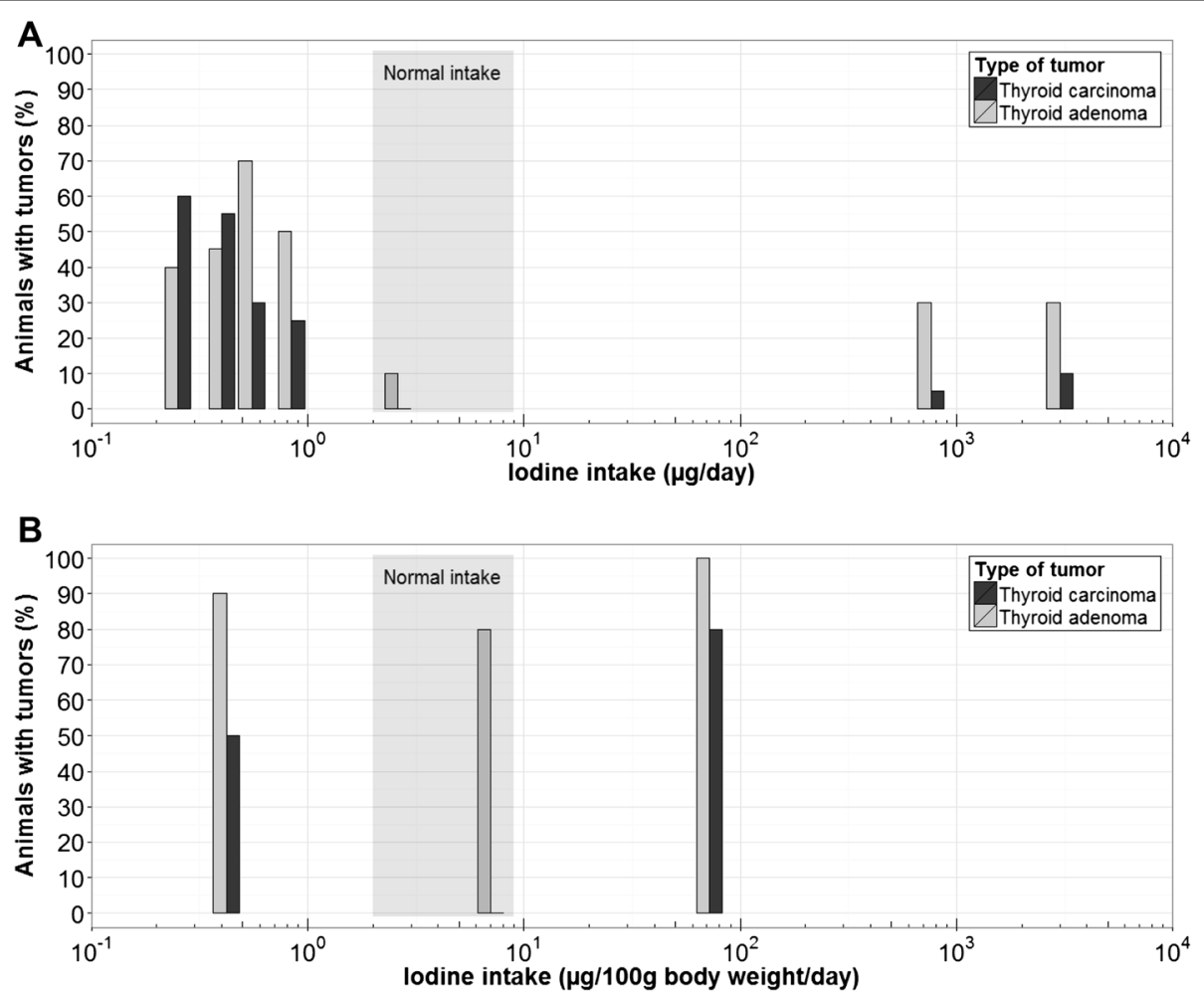

Fig. 1 Prevalence of tumors in animals versus iodine intake. a Prevalence of animals with thyroid adenoma and thyroid carcinoma at week 26 after a single $2.8 \mathrm{mg} / \mathrm{kg}$ DHPN dose at week 2 and under one of seven long-term deficient, sufficient or excessive iodine diets (deficient intake: $0.25,0.4,0.55,0.84 \mu \mathrm{g} /$ day; normal intake: $2.6 \mu \mathrm{g} /$ day; excessive intake: 760, $3000 \mu \mathrm{g} /$ day) [33]. b Prevalence of animals with thyroid adenoma and thyroid carcinoma at week 110 after a single exposure to 4-Gy external radiation at week 6 and under one of three long-term deficient, sufficient or excessive iodine diets (deficient intake: $0.42 \mu \mathrm{g} / 100 \mathrm{~g}$ body weight/day; normal intake: $7 \mu \mathrm{g} / 100 \mathrm{~g}$ body weight/day; excessive intake: $72 \mu \mathrm{g} /$ $100 \mathrm{~g}$ body weight/day) [36]. Shaded area: range of normal iodine intake. 


\section{Proposed mechanisms linking iodine intake and thyroid cancer}

\section{Chronic TSH stimulation in iodine deficiency}

Thyroid follicular cells proliferate only slowly under normal conditions, but in iodine deficient animals, serum TSH increases and the proliferation rate of thyroid cells increases by 5 to 30 -fold [36], leading to marked thyroid hyperplasia and hypertrophy. Rapidly proliferating thyrocytes are likely more vulnerable to mutagens such as radiation, chemical carcinogens and oxidative stress, and may accumulate a higher number of genetic alterations. Thyroid hyperplasia induced by iodine deficiency results in chromosomal changes in the rat thyroid, with an increased number of aneuploid cells [37]. Several authors have suggested that thyroid tumors caused by iodine deficiency are due to chronic TSH overstimulation, possibly working together with epidermal growth factor and insulin-like growth factor I [38-41]. Consistent with this hypothesis, rat studies have shown that chronic TSH stimulation induced by goitrogen-containing diets or partial thyroidectomy result in a transition from thyroid follicular adenomas to follicular carcinomas [42-44]. This hypothesis is also consistent with the findings of increased FTC and ATC in populations with severe endemic goiter, because serum TSH is increased in moderateto-severe iodine deficiency in an effort to maintain euthyroidism [16].

Excess iodide, by inhibiting thyroid hormone production (the Wolff-Chaikoff effect), can transiently increase TSH. However, in animal studies, chronic iodine excess does not increase serum TSH [36], and, in cell studies, moderate doses of iodide inhibit thyroid cell proliferation [45]. Most humans escape from the Wolff-Chaikoff effect as intrathyroidal iodide suppresses further iodide uptake via $\mathrm{Na} / \mathrm{I}$ symporter inhibition [46]. Thus, the mechanism by which iodine excess promotes thyroid tumorigenesis is uncertain. Some population studies have reported slightly higher mean serum TSH in populations with sufficient or excess iodine intakes, compared to mildly deficient populations, but this is likely due to increased toxic adenomas in mild iodine deficiency [16].

\section{lodine, oxidative damage and apoptosis}

Other mechanisms besides chronic TSH stimulation may contribute to thyroid tumorigenesis during iodine deficiency. Iodine deficiency increase $\mathrm{H}_{2} \mathrm{O}_{2}$-mediated, reactive oxygen species (ROS) generation, which can damage DNA and result in mutations [47]. Activity of antioxidant enzyme systems, including superoxide dismutase-3, are increased in iodine deficient rat thyroids, and this is accompanied by an increase of uracil and oxidized purine or pyrimidine adducts in thyroid DNA [48]. In immortalized thyroid cell cultures (TAD-2) and primary cultures of human thyroid cells, excess molecular iodide, generated by oxidation of iodine by endogenous peroxidases, induces apoptosis through a mechanism involving generation of free radicals [49]. Providing additional iodide to human thyroid cell lines reduces generation of $\mathrm{H}_{2} \mathrm{O}_{2}$ [50]. Exposure to iodine can also cause apoptosis in human thyroid cells and thyroid carcinoma cell lines through generation of iodolactones (iodinated derivatives of fatty acids) [51, 52].

\section{lodine intake and the BRAF mutation in PTC}

Molecular alterations identified in PTC result in the activation of proteins along the mitogen-activated protein kinase (MAPK) pathway and include point mutations of the $B R A F$ and $R A S$ genes and BRAF and RET rearrangements [53]. BRAF mutations or rearrangements are found in $29-83 \%$ of PTC, but are rare in FTC [54]. Several cross-sectional studies have looked at the effects of varying iodine status on the prevalence of the BRAF mutation in PTC. A study in southern Italy compared the percentage of PTC containing the $B R A F$ mutation in two regions, one iodine sufficient and one iodine deficient; the individual iodine status of the cases was not defined [55]. The prevalence of $B R A F$ positive PTCs was 107 out of 270 (39.6\%) in the iodine sufficient area and 18 out of 53 (33.9\%) in the iodine deficient area (N.S.). In China the prevalence of the BRAF mutation in PTC was significantly higher (69.2\%) in cases from a region with excessive iodine intake due to iodine rich drinking water (median UIC in the population was $>900 \mu \mathrm{g} / \mathrm{L}$ ) compared to $53.3 \%$ in PTC cases from regions with mildly deficient to sufficient iodine intakes from iodized salt (median UICs of 82$198 \mu \mathrm{g} / \mathrm{L}$ ) [56]. The overall incidence of PTC in the different regions was not reported. In contrast, in thyroid cells expressing activated $B R A F$, excess iodine may exert protective effects, attenuating acute $B R A F$ oncogene-mediated microRNA deregulation [57].

\section{lodine intake and RAS mutations in thyroid cancer}

Mutations in the RAS genes are present in 40-53\% of FTC and 6-51\% of ATC, but are rare in PTC [54]. A cross-sectional study compared the frequency of RAS oncogene mutations in thyroid tumors (25 adenomas, 16 FTC, and 22 PTC) from cases in an iodine sufficient area in Canada to cases in a mildly iodine deficient region in Hungary [58]. The RAS oncogene mutation rate was significantly higher in adenomas (85 versus $17 \%$ ) and FTC (50 versus $10 \%$ ), from the iodine deficient area than the iodine sufficient area, with no RAS mutations detected in PTC.

\section{lodine and RET rearrangements in thyroid cancer}

RET rearrangements are reported in 13-43\% of PTC, but are rare in ATC and have not been reported in FTC [54]. Fiore et al. [59] reported that excess iodine may play a protective role during $R E T / P T C 3$ oncogene activation in 
thyroid cells. They treated RET/PTC3-activated rat thyroid cells with $10^{-3} \mathrm{M}$ sodium iodide, and found a reduction in cell proliferation and attenuation of the loss of Nis and Tshr genes and protein expression induced by RET/PTC3 oncogene induction. When the human PTC cell line W3 and the FTC cell line FTC133 were incubated with excess iodine, progressively increasing iodine exposure first promoted $\left(10^{-3} \mathrm{M}\right.$ iodine $)$ and then inhibited $\left(10^{-2}\right.$ and $10^{-1} \mathrm{M}$ iodine) growth and migration of thyroid cancer cells [60]. However, it should be remembered that the physiological concentration of iodine in the human thyroid is in the range of $10^{-5}$ to $10^{-6} \mathrm{M}$. Thus, thyrocyte exposure to iodine in these cell studies was several orders of magnitude above that encountered under physiological conditions resulting from varying dietary iodine intakes.

\section{lodine intake and thyroid cancer: ecological studies Sources of potential bias}

Many ecological studies have examined the relationship between iodine intake and thyroid cancer incidence and mortality. The results of these studies should be interpreted with caution, because of multiple sources of potential bias [21]. It is difficult to compare thyroid cancer incidence across cancer registries because data collection methods are usually not standardized. The rate of thyroid microcarcinomas depends largely on the frequency and intensity of histological investigation of surgical and autopsy specimens; the higher the number of sections investigated per case, the more microcarcinomas can be found [61]. There is considerable observer variation in histological typing of thyroid cancer subtypes, particularly for FTC and mixed PTC-FTC, and this limits comparisons from different studies [62]. Comparing thyroid cancer rates across different time periods is biased by differences in histological classification, due to changes in 1974 and 1988 in the WHO classification system for thyroid cancer [63]; in 1988, WHO specified that all FTC presenting a papillary component should be considered PTC, and this likely contributed to the increase in the ratio of PTC:FTC in many countries after the classification change [64].

Because of its relatively low incidence, comparing rates of thyroid cancer between populations requires long periods of observation and this increases the likelihood of confounding from other risk factors that may have changed over the same time period. Also, there is likely to be a latency period after exposure of susceptible individuals to iodine excess or deficiency and subsequent changes in the thyroid cancer incidence. The length of this latency period is not known, with experts suggesting it could be 15 to 40 years $[17,65,66]$. There is also a long latency period in the elimination of goiter in endemic populations: for example, in central Switzerland, after three decades of salt iodization, the prevalence of goiter was $<5 \%$ in schoolchildren but was still $75 \%$ in $50-60$ yearolds [67]. An abrupt increase or decrease in population iodine intake might be expected to produce a period effect if all age groups were similarly affected, or a cohort effect if the effect were limited to a vulnerable age, such as childhood. Whether these effects confound longitudinal studies is uncertain.

It is particularly difficult to reliably compare thyroid cancer rates in populations with and without endemic goiter as a proxy for varying iodine intake. Ascertainment bias is high in these studies due to differences in the work-up of goiter and nodules, the frequency of surgical operations, and the indication for operation and preoperative diagnostic methods. The ratio of surgically removed goiters to non-operated goiters tends to be higher in non-endemic areas, because willingness of patients and physicians to perform operations is usually lower in endemic goiter areas. Also, because presence of a thyroid nodule has a higher likelihood of malignancy in iodine sufficient areas free of endemic goiter, there may be differences in diagnostic work-up [21].

Finally, in many countries, the introduction of iodized salt and an increase in iodine intake has coincided with the more widespread use of improved thyroid diagnostic tools (e.g., ultrasound, fine-needle biopsy and thyroid scintigraphy) and corresponding increases in incidence of PTC, often clinically silent. In France, an increase in the use of thyroid ultrasound in patients referred for evaluation of a thyroid disorder (from 3 to $85 \%$ ) and of cytology (from 4.5 to $23 \%$ ) was associated with an increase in PTC incidence [68]. This introduces strong ascertainment bias in longitudinal or before and after studies favoring a higher incidence of PTC in more recent surveys. Thus, evidence from older longitudinal studies done before this increase in diagnostic intensity may be more valid than newer studies.

\section{lodine intake and differentiated thyroid cancer}

Differentiated thyroid cancer, comprising PTC, FTC and, rarely, Hürthle cell thyroid cancer, makes up about $95 \%$ of all thyroid cancers. The following section discusses the possible links between changes in iodine intake and changes in rates of differentiated thyroid cancer in selected countries. In this section, Fig. 2a-c that plot country data on median UIC as a proxy for iodine intake versus incidence of thyroid cancer use comparable data from the Cancer Incidence in Five Continents (CI5) up to 2007 [69].

\section{The U.S.}

Based on the national UIC data from successive National Health and Nutrition Examination Surveys (NHANES IIII), the U.S. population had excessive iodine intake in 


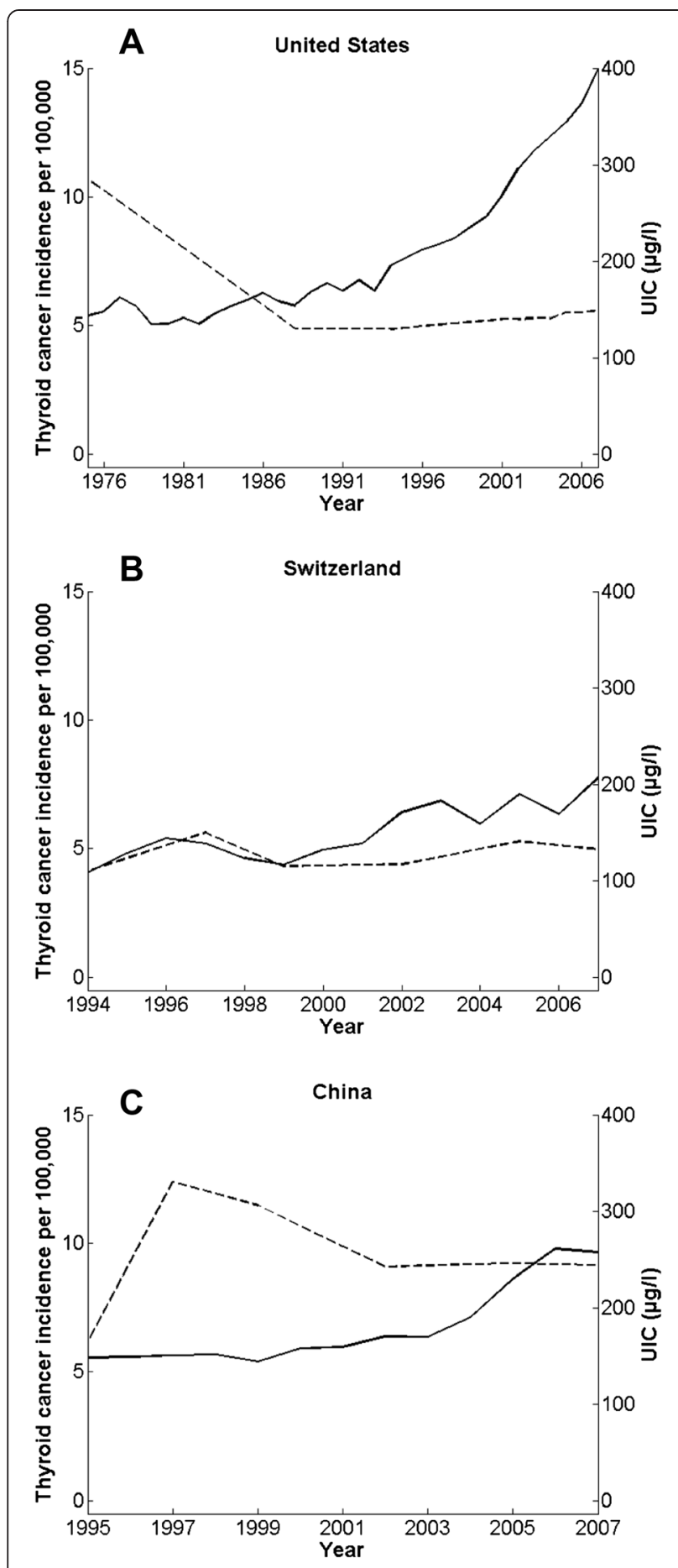

Fig. 2 Thyroid cancer incidence and urinary iodine concentration evolution. National median urinary iodine concentration (UIC) (dashed line) as a proxy for iodine intake and age-standardized incidence rate of differentiated thyroid cancer (number of new cases per 100,000 per year) (solid line) in females of all ages in a United States, b Switzerland, and c China. Country data are from the Cancer Incidence in Five Continents (Cl5) up to 2007 [69]. the early 1970s (a median UIC of $320 \mu \mathrm{g} / \mathrm{L}$ ), a more than $50 \%$ decrease in iodine intakes to a median UIC of $145 \mu \mathrm{g} / \mathrm{L}$ in 1988 through 1994 [70], followed by sufficient and stable intakes during the period 2000-2010, with females having a median UIC of $142 \mu \mathrm{g} / \mathrm{L}$ and males a median UIC of $176 \mu \mathrm{g} / \mathrm{L}$ [71]. During this same period, incidence of thyroid cancer in the U.S. has been increasing by $6.6 \%$ annually, and from 1973 to 2013, the annual incidence has increased by more than $500 \%$ [72]. Thus, as shown in Fig. 2a, over past 4 decades in the U.S., while national iodine intakes have fallen from excess levels of intake to stabilize in the adequate range, there has been a steady increase in national incidence of differentiated thyroid cancer.

\section{Northern Europe}

Petersson et al. [73], using maps of goiter prevalence in Sweden from the 1930s to define iodine deficient versus iodine sufficient areas, found that during the period of 1958-1981, the relative risk of developing thyroid cancer was 0.92 in Swedish regions that were historically iodine deficient versus iodine sufficient. However, there was likely misclassification of exposure status as low-level iodine prophylaxis had been introduced in the formerly deficient areas before the study period. During the study period, the iodization level in salt was increased from 10 to $50 \mathrm{ppm}$ and the iodine level in cattle feed supplements was increased, yet incidence rates of PTC increased similarly in both the iodine deficient and iodine sufficient regions, suggesting that the increasing rates were not related to original differences in iodine intakes.

Denmark introduced mandatory national fortification of salt used for bread making in 2000 and $>90 \%$ of Danish bread now contains iodized salt. This has improved iodine intakes but adults remain mildly iodine deficient with a median UIC of $83 \mu \mathrm{g} / \mathrm{L}$ because the fortification level is low, at $13 \mathrm{ppm}$ [74]. The mean annual increase in the incidence of thyroid cancer in Denmark from 1943 to 2008 was $1.7 \%$ in men and $1.8 \%$ in women and was almost exclusively PTC [75]. The strongest increase in incidence began in the years before the iodization of salt, likely due to increased diagnostic activity. Because of differences in groundwater iodine content, before the introduction of iodized salt, the eastern part of Denmark was mildly iodine deficient (median UIC of $61 \mu \mathrm{g} / \mathrm{L}$ ), while the western part was moderately deficient (median UIC of $45 \mu \mathrm{g} / \mathrm{L}$ ). Although palpable goiter was found in $14.6 \%$ in the area of moderate iodine deficiency versus $9.8 \%$ in the area of mild deficiency [76], there were no regional differences in the overall incidence of thyroid cancer [77]. Also, the introduction of iodized salt did not result in a greater increase in the incidence of PTC in moderately iodine deficient western Denmark compared to eastern Denmark, suggesting that 
variations in iodine status are not a primary risk factor for thyroid cancer in the country [77].

In the Netherlands, the incidence of PTC has increased by only $2.1 \%$ per year between 1989 and 2003, a less pronounced increase than in many other countries [78]. This might be partly explained by the stable and sufficient iodine intake of the Dutch population during the last 4 decades, together with the low level of radiation exposure and possibly the more conservative approach to incidentally discovered thyroid nodules [78].

The incidence of thyroid cancer is high in Iceland, a country with excess iodine intake from seafood and milk. In a study of surgical specimens for the period of 1944 to 1964 comparing Iceland and northern Scotland (where iodine intakes were presumed to be adequate), the PTC:FTC ratio was 6.5 in Iceland and 3.6 in Scotland [79]. The age-specific incidence rates for papillary carcinoma were approximately five times higher in Iceland than in Scotland in adults older than 35 years of age. It was hypothesized that high iodine intakes contribute to the high incidence of thyroid cancer in Iceland [79], but other authors have argued the high rates are due to the volcanic nature of the island [21]. Natural radiation is higher in volcanic areas, and radiation is known to increase risk for thyroid cancer, especially when the radiation occurs in childhood [21].

\section{Central Europe}

To correct severe endemic goiter and cretinism, iodized salt was introduced to northeastern Switzerland in 1923, and gradually spread to all Swiss cantons. In 1962, the iodine content in salt was increased from 5 to $10 \mathrm{ppm}$. A study analyzing more than 90'000 surgical specimens using the 1974 WHO classification reported a significant shift in the distribution of thyroid cancer subtypes comparing the period 1925 through 1941 to the period 1962 through 1973 [67]. In the former period, using ageadjusted data, $40 \%$ of thyroid cancer was FTC, $38 \%$ ATC and only $8 \%$ was PTC. In the later period, $33 \%$ were PTC, $30 \%$ were FTC and $24 \%$ were ATC. In a review of Swiss studies before 1973, the female:male ratio of thyroid cancer in areas of endemic goiter was 1.4 to 1.6, compared to those areas goiter-free or areas with iodized salt programs, where the female:male ratio was 2.1 to 3.0 [67]. In Geneva, between 1970-74 and 1995-98, when the iodine content and distribution of iodized salt did not change, the incidence of PTC increased from 0.7 to $1.8 / 100,000$ for men and from 3.1 to $4.3 / 100,000$ for women [64]. The authors suggested that the increasing incidence of PTC was mainly due to improved screening and diagnostic activity [64]. Figure $2 \mathrm{~b}$ shows the relationship between Swiss national UIC data and national incidence of thyroid cancer for the period of 1994-2007; while iodine intakes in the population have remained stable, the prevalence of thyroid cancer has steadily increased.

In Germany, between 2003 and 2008, during which the country had sufficient iodine intakes from voluntary iodization of salt, the incidence rate of thyroid cancer rose from 2.7 to 3.4 (men) and from 6.5 to 8.9 (women) per 100,000 per year and was mainly PTC [80]. The incidence rate was higher in southern Germany, and the authors suggested this might be attributed in part to long-standing differences of iodine intake between different German regions, with the southern part of the country historically an area of iodine deficiency and endemic goiter.

Iodized salt was introduced into Austria in 1962 at a fortification level of $10 \mathrm{ppm}$. A study of thyroid cancer in surgical specimens in central Austria from 1952 to 1975 showed a significant increase in differentiated thyroid cancer and in the ratio of PTC:FTC, from 0.2 in $1952-1959$ to 0.87 in 1970 to 1975 [66].

\section{Southern Europe}

Italy has one of the highest incidence rates for thyroid cancer; in 2007, the age-standardized (world population) incidence rate in women was nearly 20 per 100,000 women [1]. An Italian study analyzed thyroid cancer incidence from 25 cancer registries throughout the country between 1991 and 2005, before the national salt iodization program was introduced [81]. Populations located near the Alps and the Apennine Mountain Ranges, where iodine in soil and water is lowest, had low incidence rates for PTC compared to areas with higher iodine intake. However, the authors suggested this distribution of PTC was likely explained by local differences in medical surveillance, rather than iodine intake [81]. In a populationbased study of $\approx 5600$ subjects in Sicily in two regions with different iodine intakes during the period 1980 to 1990, surgery was performed in 792 patients on the basis of fine-needle biopsy of cold thyroid nodules. The frequency of thyroid cancer in patients with cold nodules was $5.3 \%$ in the iodine sufficient area (mean UIC $114 \mu \mathrm{g} / \mathrm{L}$ ) and $2.7 \%$ in the iodine deficient area (mean UIC $<50 \mu \mathrm{g} / \mathrm{L}$ ) but was significantly different only in females [82].

A study in southern Greece examined patterns of thyroid cancer during the period from 1963 to 2000 [83]. The proportion of PTC was significantly higher in cases born in iodine sufficient areas $(84 \%, n=162 / 193)$ than in cases born in previously iodine deficient areas $(74 \%$, $n=159 / 214$ ), while the iodine status of the current area of residence was not related to histological type [83].

In northwestern Spain, iodized salt was introduced in 1985. Rego-Iraeta et al. [84] studied rates of thyroid cancer during the period of 1978 to 2001 during the population's transition from mild iodine deficiency to iodine sufficiency. Comparing the years before and after salt 
iodization, the PTC:FTC ratio increased from 2.3 to 11.5 , and the thyroid cancer incidence increased in females from $1.56 / 100,000$ in the period from 1978 to 1985 to $8.23 / 100,000$ in period from 1994 to 2001 , with most of the new cases being papillary microcarcinomas [84].

\section{China}

Several Chinese studies have pointed out the temporal association between the introduction of the national program of mandatory salt iodization in 1996 and a subsequent increase in incidence of PTC [85, 86]. As shown in Fig. 2c, during the period from 1997 to 2002, the national median UIC has fallen and then remained stable, while the national incidence of thyroid cancer has steadily increased. In Shanghai, from 1983 to 2007, the annual percentage change in thyroid cancer incidence in women was $4.9 \%$ from 1983 to 2003 and $19.9 \%$ afterward [85]. Teng et al. [87] did a five-year follow-up study of thyroid disorders in three regions of China, one with highly excessive iodine intakes from iodine-rich drinking water (median UIC of $635 \mu \mathrm{g} / \mathrm{L}$ ), one with mildly excessive intakes from iodized salt (median UIC of $350 \mu \mathrm{g} / \mathrm{L}$ ) and one that was borderline iodine deficient (median UIC of $97 \mu \mathrm{g} / \mathrm{L}$ ). No significant differences among cohorts were found in the cumulative incidence of either single or multiple thyroid nodules, but the region with highly excessive intakes had 13 new cases of thyroid cancer while none were diagnosed in the other two regions [87]. In contrast, a large cross-sectional study found no correlation between iodine status and the prevalence of thyroid cancer in a coastal region of China [88]. A large cross-sectional study in Hangzhou in 2010 found a higher risk of thyroid nodules in adults consuming noniodized salt versus iodized salt (odds ratio (OR): 1.36; $95 \%$ CI: 1.01, 1.83) and a higher risk of thyroid nodules in those with low iodine intakes, but not excess iodine intakes [89]. There have been changes in other suspected risk factors for thyroid cancer in China over recent decades, including increasing exposure to industrial pollution [90] and increasing adiposity [91]. Moreover, rapid improvements in health care during the same period have led to increasing diagnostic intensity for thyroid cancer, and this bias likely explains a major portion of the increasing thyroid cancer incidence in China.

\section{Australia}

Burgess et al. [92, 93] using data from Tasmania's and other regional cancer registries in Australia has reported regional and national thyroid cancer incidence and mortality trends, and related them to iodine status of the population. Tasmania and much of the Australian Eastern Seaboard were historically iodine deficient until about 1970, when a combination of iodization of bread (in Tasmania) and use of iodophors in the dairying industry improved iodine intakes. Iodized bread was discontinued in 1974 and the use of iodophors in dairying decreased in the early 1980s, resulting in the return of mild-to-moderate iodine deficiency in the 1980s and 1990s. In 1996, the median UIC in Tasmania had fallen to $42 \mu \mathrm{g} / \mathrm{L}$, and in 2004, median UICs in the eastern states of Australia were 74 to $89 \mu \mathrm{g} / \mathrm{L}$, indicating mild iodine deficiency [94]. During this period of falling and then deficient iodine intakes, for the period 1978-1998 in Tasmania [92] and for the rest of Australia from 1982-1997 [93], thyroid cancer incidence rates increased steadily. In the latter study, the increase was $6.7 \%$ per year for females and $4.4 \%$ per year for males, primarily due to a rise in PTC incidence. The average annual increase in PTC incidence was most marked in moderately-iodine deficient Tasmania ( $24.7 \%$ per annum) and mildly iodine deficient Victoria (13.2 \%), New South Wales (10.1\%) and Queensland (14.1\%), compared to the presumed iodine sufficient western states (4.0-8.9\%) [93].

\section{Argentina}

In a study from northern Argentina of the period from 1958 to 2007, where iodized salt was introduced in 1963, the incidence rate for thyroid cancer showed a progressive increase from 1.6 per 100,000 in 1960 to 3.6 per 100,000 in 2001, and the ratio of PTC:FTC increased from 1.7 to 3.9 [95].

\section{lodine intake and undifferentiated thyroid cancer}

Although ATC is a rare form of thyroid cancer, accounting for less than $5 \%$ of thyroid cancer in most countries, patients with ATC have a poor prognosis, and thus mortality from ATC accounts for most of the mortality from thyroid cancer [96]. In contrast to differentiated thyroid cancer, which often has a subtle clinical presentation and may be difficult to detect, ATC is correctly diagnosed in nearly all cases in countries with adequate health care because of rapid tumor growth and clinical presentation. Also, its highly specific histological features are easy to recognize [97]. Thus, compared to differentiated thyroid cancer, varying diagnostic intensity or criteria are much less likely to bias changes in ATC incidence rates within countries over time. For these reasons, ecological studies that describe changes in ATC incidence before and after introduction of iodized salt may be more reliable than for differentiated thyroid cancer.

Before and after studies of the effect of iodine prophylaxis on ATC have mainly been done in areas of historic endemic goiter in Europe. Bacher-Stier et al. [98] reported on changes in ATC in the Tyrol region of Austria. In the early 1960s, this area was moderately iodine deficient (mean UIC was $36 \mu \mathrm{g}$ iodine/g creatinine) and goiter was endemic. Iodized salt fortified at level of $10 \mathrm{ppm}$ was introduced in 1963 and at $20 \mathrm{ppm}$ in 1992, and this resulted in iodine sufficiency and a mean UIC 
of $145 \mu \mathrm{g}$ iodine/g creatinine by the mid-1990s. Overall incidence of thyroid cancer did not change from 1952 to 1995, but there was a marked shift in the percentage of thyroid cancer that was ATC, from $28.6 \%$ in 1952-1976 to $4.9 \%$ in 1986-1995 [98].

In Slovenia, edible salt was fortified with $10 \mathrm{ppm}$ iodine from 1972 to 1997 and the population was mildly iodine deficient with a mean UIC of $83 \mu \mathrm{g}$ iodine/g creatinine [97]. Salt iodization was increased to $25 \mathrm{ppm}$ from 1998 to 2008 and this resulted in adequate iodine intakes and a mean UIC of $148 \mu \mathrm{g}$ iodine/g creatinine. The annual incidence of ATC in Slovenia before 1998 was 3.25 per million versus 1.9 per million afterward [97]. From 1981 to 1995 in southern Germany, iodine status improved from moderate iodine deficiency (median UIC of $40 \mu \mathrm{g} / \mathrm{L}$ ) in 1986 to mild iodine deficiency (median UIC of $72 \mu \mathrm{g} / \mathrm{L}$ ) in 1997, and the percentage of thyroid cancer that was ATC decreased from $11.3 \%$ to $7.3 \%$ [99]. Other studies have described similar decreases in ATC after correction of iodine deficiency through iodized salt in Switzerland, Austria, Italy and Sweden [66, 67, 73, 100]. Along with improved medical care, the significant decrease in the incidence of ATC after the introduction of iodized salt in Switzerland may have contributed to the marked decrease in mortality from thyroid cancer between 1921 and 1978 [101].

However, it should be noted that other European countries have reported similar reductions in ATC without changes in population iodine intake. In Scotland, there has been a decrease in the incidence of ATC without changes in iodination policy [102]. Similarly in the Netherlands, where iodine intakes have been stable and sufficient over the past few decades, the incidence of ATC decreased by $7.1 \%$ per year between 1989 and 2003 [78].

Northern Argentina in 1960 was severely iodine deficient and mean UI excretion was $20 \mu \mathrm{g} /$ day [103]. After iodized salt was introduced, mean UIC increased into the sufficient range, and was $152 \mu \mathrm{g}$ iodine/g creatinine in 1975. Over this period, the percentage of thyroid cancer that was ATC decreased from $15.2 \%$ before salt iodization to $2.6 \%$ after salt iodination, and the annual incidence decreased from 1.4 per million to 0.1 per million [103]. A plausible explanation for why the percentage of thyroid cancer that is ATC is higher in areas of severe iodine deficiency is that when goiter is endemic in a population, individuals are less concerned by the occurrence of thyroid nodules or swelling, and this may delay diagnosis in many cases until serious symptoms occur. This delay in recognition may allow initially well-differentiated thyroid cancer to change into anaplastic cancer $[104,105]$.

\section{Conclusions}

Table 2 summarizes the before and after studies looking at either the effect of the introduction of salt iodization or an increase in the salt iodization level on patterns of thyroid cancer. In three of eight studies that reported the gender ratio of thyroid cancer, the female: male ratio increased, while in two it decreased and in three it remained unchanged. The studies show a shift in the subtypes of thyroid cancer: all studies report an increase in the PTC:FTC ratio, and all but one show a decrease in the percentage of ATC. No studies have found an increase in incidence or frequency of ATC with increasing iodine intake. The findings in Table 2 are consistent with the earlier review of Williams [22], who reported that in countries with 'high' iodine intake (U.S., Iceland) the ratio of PTC:FTC ranged from 3.4 to 6.5, while in countries with 'moderate' iodine intake (the U.K. and northern Germany) the ratio was from 1.6 to 3.7 , and in countries with 'low' iodide intake (Argentina, Columbia, Finland, southern Germany, Austria and Switzerland) the ratio was from 0.19 to 1.7 .

Although the data in Table 2 suggest that populations in areas of sufficient iodine intake seem to have fewer of the more aggressive ATC and FTC, but more PTC, the comparisons may have been biased by other factors that may influence the presentation of thyroid cancer besides iodine intake. Interestingly, the increase in the PTC:FTC ratio and the decline in ATC is evident even in the study periods that preceded the introduction of increased diagnostic intensity for thyroid cancer. However, it should be remembered that increases in the incidence of differentiated thyroid cancer and the PTC:FTC ratio over the past two decades have occurred in countries with decreasing, stable and increasing iodine intakes. As shown in Fig. 2a-c, during the past several decades in the U.S., the incidence of thyroid cancer has been steadily increasing, but iodine intakes during the same period have decreased by about $50 \%$, and in Switzerland and China, two countries with well-established salt iodization programs, although iodine intakes have been stable, there have been steady increases in the incidence of thyroid cancer.

\section{lodine intake and mortality from thyroid cancer}

In most areas of the world, while the incidence of thyroid cancer has been increasing over the past few decades, mortality has steadily declined [1]. Decreases in thyroid cancer mortality are due mainly to improved early diagnosis and surgery or ${ }^{131} \mathrm{I}$ therapy applied at an early tumor stage. However, because current or a history of goiter or thyroid nodules are strong risk factors for thyroid cancer [15], particularly the more aggressive subtypes (discussed below), it is possible that the substantial decline in iodine deficiency in many countries - particularly in low and middle-income areas that have introduced iodized salt- might also be contributing to the favorable trends in thyroid cancer mortality. 
Table 2 Before-and-after studies on the effect of salt iodization on type of thyroid cancer. The effect of introduction of salt iodization or an increase in the salt iodization level on the sex ratio (female: male, F:M) of affected subjects and the subtypes of thyroid cancer, by country: changes in the papillary thyroid cancer to follicular thyroid cancer ratio (PTC:FTC), and the percentage of anaplastic thyroid cancer (\% ATC).

\begin{tabular}{|c|c|c|c|c|c|c|c|}
\hline \multirow[t]{2}{*}{ Country (reference) } & \multicolumn{3}{|c|}{ Years pre-iodized salt } & \multirow[t]{2}{*}{ Year and change in salt iodization } & \multicolumn{3}{|c|}{ Years post-iodized salt } \\
\hline & PTC:FT & $\%$ ATC & $\mathrm{F}: \mathrm{M}$ & & PTC:FTC & $\%$ ATC & $\mathrm{F}: \mathrm{M}$ \\
\hline \multirow[t]{2}{*}{ Basel, Switzerland [148] } & \multicolumn{3}{|c|}{$1944-1953$} & 1962 & \multicolumn{3}{|c|}{ 1964-1973 } \\
\hline & 0.27 & 28.7 & 2.5 & Increase from 5 to $10 \mathrm{ppm}$ & 0.74 & 27.7 & 2.5 \\
\hline \multirow[t]{2}{*}{ Zurich, Switzerland [67] } & \multicolumn{3}{|c|}{$1925-1941$} & 1962 & \multicolumn{3}{|c|}{$1962-1973$} \\
\hline & 0.19 & 36.9 & 1.3 & Increase from 5 to $10 \mathrm{ppm}$ & 1.1 & 23.8 & 2.1 \\
\hline \multirow[t]{2}{*}{ Innsbruck, Austria [66] } & \multicolumn{3}{|c|}{ 1952-1959 } & 1963 & \multicolumn{3}{|c|}{ 1970-1975 } \\
\hline & 0.21 & na & 0.9 & Introduction at $10 \mathrm{ppm}$ & 1.1 & na & 1.9 \\
\hline \multirow[t]{2}{*}{ Tyrol, Austria [98] } & \multicolumn{3}{|c|}{ 1952-1975 } & 1963; 1992 & \multicolumn{3}{|c|}{ 1986-1995 } \\
\hline & 0.55 & 28.4 & na & Introduction at $10 \mathrm{ppm}$; increase to $20 \mathrm{ppm}$ & 1.5 & 4.9 & na \\
\hline \multirow[t]{2}{*}{ Klagenfurt, Austria [149] } & \multicolumn{3}{|c|}{ 1984-1989 } & 1992 & \multicolumn{3}{|c|}{ 1990-1995 } \\
\hline & 2.6 & na & na & Increase from 10 to $20 \mathrm{ppm}$ & 4.0 & na & na \\
\hline \multirow[t]{2}{*}{ Krakow and Nowy Sacz, Poland [150] } & \multicolumn{3}{|l|}{1986} & 1997 & \multicolumn{3}{|l|}{2001} \\
\hline & 1.0 & na & na & Introduction at $30 \mathrm{ppm}$ & 5.9 & na & na \\
\hline \multirow[t]{2}{*}{ Lower Franconia, Germany [99] } & \multicolumn{3}{|c|}{$1981-1985$} & 1993 & \multicolumn{3}{|c|}{$1991-1995$} \\
\hline & 1.5 & 11.3 & 3.0 & Increased use by the food industry at $20 \mathrm{ppm}$ & 3.4 & 7.3 & 2.2 \\
\hline \multirow[t]{2}{*}{ Salta, Argentina [95] } & \multicolumn{3}{|c|}{ 1958-1972 } & $1963 ; 1970$ & \multicolumn{3}{|c|}{$1985-2007$} \\
\hline & 1.7 & 16.9 & 2.9 & Introduction at $40 \mathrm{ppm}$; decrease to $33 \mathrm{ppm}$ & 3.9 & 6.4 & 4.0 \\
\hline \multirow[t]{2}{*}{ Galicia, Spain [84] } & \multicolumn{3}{|c|}{ 1978-1985 } & 1985 & \multicolumn{3}{|c|}{ 1994-2001 } \\
\hline & 2.3 & na & 4.3 & Introduction at $60 \mathrm{ppm}$ & 11.5 & na & 3.4 \\
\hline \multirow[t]{2}{*}{ Parma, Italy [100] } & \multicolumn{3}{|c|}{ 1998-2003 } & 2005 & $2004-2$ & & \\
\hline & 13.0 & 2.3 & 3.1 & Introduction at $30 \mathrm{ppm}$ & 13.6 & 1.0 & 3.2 \\
\hline Shenyang, China [86] & 1992-1 & & & $1995 ; 2000$ & $1997-2$ & & \\
\hline & 2.3 & 7.1 & 3.2 & Introduction at 20-60 ppm; decrease to $35 \mathrm{ppm}$ & 21.9 & 2.1 & 3.6 \\
\hline
\end{tabular}

If population iodine status is a determinant of the pathogenesis of thyroid cancer, one might expect mortality rates in countries to be correlated with population iodine status. La Vecchia et al. [1], using data for thyroid cancer mortality and population size for countries in the period 1970-2012 from the WHO online database [106] estimated age-adjusted death rates from thyroid cancer at all ages in 2000 (1998-2002) and in 2010 (20082012) and percentage changes between these periods (Additional file 1: Table S1). Using these country data on thyroid cancer mortality, together with national or subnational median UIC data for same time periods, where available [18, 107], we calculated the change in ageadjusted death rates from thyroid cancer by gender between 2000 and 2010 versus the change in the population median UIC $(\mu \mathrm{g} / \mathrm{L})$ for the same time periods (Fig. 3). For women, there was a weak but significant indirect correlation $\left(\mathrm{r}^{2}=0.135 ; p=0.046\right)$ that was not present for men. These country data suggest that, for women only, a greater increase in iodine intake over the period 2000 to 2010 is associated with a greater decrease in thyroid cancer mortality.

\section{lodine intake and occult thyroid carcinoma at autopsy}

Occult thyroid carcinomas (OTC) are often incidentally found at autopsy, and nearly all are papillary microcarcinomas. Unlike clinical PTC, differences in the occurrence of OTC at autopsy are not influenced by differences in screening and diagnostic intensity, but more likely reflect true differences due to genetic and/or environmental factors [108]. Although differences in autopsy methods used for thyroid sectioning and histological examination may bias comparisons, associations between iodine intake in populations and the occurrence of OTC at autopsy may be relatively free of ascertainment bias and therefore valuable.

Kovacs et al. [109] compared rates of OTC at autopsy in two ethnically and socioeconomically comparable populations in Hungary, one in an iodine deficient area (median UIC of $70 \mu \mathrm{g}$ iodine/g creatinine) and one in an 

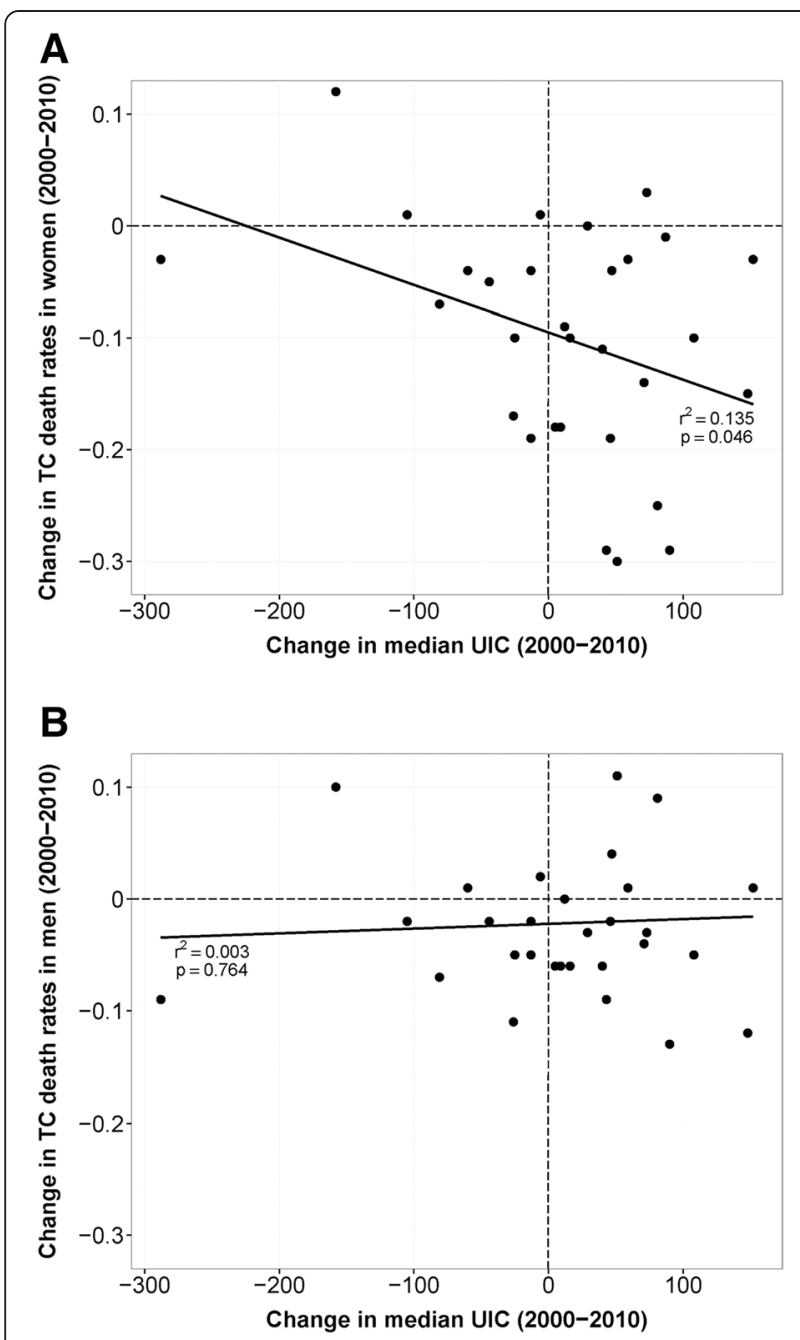

Fig. 3 Change in thyroid cancer death rates versus change in median urinary iodine concentration. Correlation plot of change in age-adjusted (world population) death rates from thyroid cancer (TC) at all ages in $\mathbf{a}$ women and $\mathbf{b}$ men between 2000 and 2010 versus national or large subnational population median urinary iodine concentration $(\mathrm{UIC})(\mu \mathrm{g} / \mathrm{L})$ for the same time periods. Each data point represents one country. National thyroid cancer death rates are from La Vecchia et al. [1] and UIC data are from the lodine Global Network [18] and WHO VMNIS [107]. Coefficient of determination $r^{2}$ and $p$-value are derived from the linear regression model.

area of iodine excess due to iodine-rich drinking water (median UIC of $500 \mu \mathrm{g}$ iodine/g creatinine). Goiter prevalence was $22.5 \%$ in the iodine deficient area versus $2.3 \%$ in the iodine excess area, and thyroid nodularity was more common in the iodine deficient area. However, the occurrence of OTC in the two areas was not different: 4.95 and $4.52 \%$, respectively, and OTC were not more common in glands with nodular goiter, consistent with findings from an earlier Austrian study [110]. In contrast, in autopsy studies performed in Japan [111] and Finland [112], OTC was more common in glands with nodular goiter.
Table 3 shows the occurrence of OTC in autopsy series, categorized by population iodine status based on the median UIC at the time of the study. Because migration studies suggest that Japanese ethnicity is a strong determinant of risk for OTC [108], we analyzed the data in Table 3 without the five Japanese autopsy studies shown at the bottom of the table. We also excluded as an outlier a Finnish study that reported a prevalence of OTC of $35.6 \%$ [112]. In the remaining studies, that examined mainly Caucasian and Hispanic populations, in areas with deficient $(n=11)$, sufficient $(n=10)$, and excessive iodine intake $(n=10)$, the weighted mean prevalence of OPTC was 5.3, 6.0 and $3.3 \%$, respectively. Comparing the weighted means, the prevalence of OTC was significantly lower $(p<0.01)$ in areas of excess iodine intake versus areas of sufficient and deficient intakes, but there was no significant difference comparing rates between areas of deficient and sufficient intakes. These data differ from two previous reviews that suggested higher iodine intakes were associated with an increase in prevalence of OTC at autopsy [22, 109]. However, the first review may have been affected by misclassification bias as iodine status was only broadly defined as high, moderate and low and criteria for this classification were not given [22]. The conclusions of the second review are limited in that nearly all of the iodine deficient populations included were Caucasian, while nearly all the iodine excessive populations were Japanese [109].

\section{Goiter, benign thyroid nodules and thyroid cancer}

Iodine deficiency sharply increases risk of nodules and goiter in populations [19]. In nodular goiter, distinct clusters of follicular cells are proliferating independent of TSH control [113]. Iodine deficiency may trigger formation of nodules through chronic stimulation by TSH and/or the mutagenic effects of increased reactive oxygen species in the iodine deficient thyroid [114]. Franceschi et al. [15] did a pooled analysis of case-control studies of benign nodules and goiter and thyroid cancer, including 2519 cases (2008 were PTC) and 4176 controls from 11 studies of goiter and 8 studies of benign nodules/adenomas. The studies of goiter included populations from five regions with sufficient to excessive iodine intakes (four studies from the U.S. in the early 1980s, and one from Japan) and six populations with sufficient to mildly deficient intakes (one from coastal China before the introduction of iodized salt and five from Europe). For women, ORs for a history of goiter for all thyroid cancer were 5.9 (95 \% CI: 4.2, 8.1), and for PTC and FTC were 5.5 (3.9, $7.8)$ and $6.9(3.8,12.4)$, respectively. For men, the OR for all thyroid cancer was 38.3 (95 \% CI: 5.0, 291.2). In that review, with the exception of a Japanese study where the OR for thyroid cancer was very high for women (26.5), the individual ORs from the other ten studies did not vary 
Table 3 Prevalence of occult thyroid cancer in adults at autopsy, by national iodine status. National population iodine status at the time of study as categorized according to WHO criteria for the median urinary iodine concentration (UIC) [23]. ${ }^{\text {a }}$

\begin{tabular}{llll}
\hline Country (reference) & Year & $\begin{array}{l}\text { No. autopsy } \\
\text { cases }\end{array}$ & $\begin{array}{l}\text { \% with occult } \\
\text { thyroid cancer }\end{array}$ \\
\hline
\end{tabular}

Probable deficient iodine intake (UIC $<100 \mu \mathrm{g} / \mathrm{L})(n=11)$

$\begin{array}{llrr}\text { Italy [151] } & 1982 & 111 & 3.6 \\ \text { Chile [152] } & 1984 & 274 & 2.9 \\ \text { Poland [108] } & 1975 & 110 & 6.6 \\ \text { Portugal [153] } & 1979 & 600 & 1.0 \\ \text { Israel [154] } & 1981 & 260 & 4.2 \\ \text { Germany [155] } & 1987 & 1020 & 6.1 \\ \text { Spain [156] } & 1993 & 100 & 22.0 \\ \text { Belarus [157] } & 1993 & 215 & 8.8 \\ \text { Ukraine [158] } & 1996 & 162 & 10.8 \\ \text { Guatemala [159] } & 2005 & 150 & 2.0 \\ \text { Hungary [109] } & 2005 & 222 & 5.0 \\ \text { Mean } & & & 6.6 \\ \text { Weighted mean } & & & 5.3\end{array}$

Probable sufficient iodine intake (UIC $=100-299 \mu \mathrm{g} / \mathrm{L})(n=10)$

$\begin{array}{llll}\text { Canada [108] } & 1975 & 100 & 6.0 \\ \text { Sweden [160] } & 1981 & 500 & 6.4 \\ \text { USA [161] } & 1988 & 138 & 2.9 \\ \text { Brazil [162] } & 1989 & 300 & 1.0 \\ \text { Argentina [163] } & 1989 & 100 & 11.0 \\ \text { Iceland [164] } & 1992 & 199 & 6.0 \\ \text { Singapore [165] } & 1994 & 444 & 9.0 \\ \text { Austria [110] } & 2001 & 118 & 8.6 \\ \text { Greece [166] } & 2002 & 160 & 5.6 \\ \text { Turkey [167] } & 2011 & 108 & 3.7 \\ \text { Mean } & & & 6.0 \\ \text { Weighted mean } & & & \end{array}$

Probable excessive iodine intake (UIC $\geq 300 \mu \mathrm{g} / \mathrm{L})(n=10)$

$\begin{array}{lrrr}\text { USA [168] } & 1952 & 429 & 0.9 \\ \text { USA [169] } & 1955 & 1000 & 2.8 \\ \text { USA [170] } & 1955 & 221 & 1.4 \\ \text { USA [171] } & 1964 & 100 & 4.0 \\ \text { USA [172] } & 1966 & 300 & 2.7 \\ \text { USA [173] } & 1969 & 220 & 0.5 \\ \text { USA [174] } & 1974 & 157 & 5.7 \\ \text { Columbia [108] } & 1975 & 607 & 5.6 \\ \text { Hungary [109] } & 2005 & 221 & 4.5 \\ \text { Brazil [175] } & 2006 & 166 & 7.8 \\ \text { Mean } & & & 3.6 \\ \text { Weighted mean } & & & \end{array}$

Weighted mean 3.3
Table 3 Prevalence of occult thyroid cancer in adults at autopsy, by national iodine status. National population iodine status at the time of study as categorized according to WHO criteria for the median urinary iodine concentration (UIC) [23]. ${ }^{a}$ (Continued)

\begin{tabular}{lccc}
\hline \multicolumn{4}{l}{ Studies of Japanese populations in areas of excessive iodine intake $(n=5)$} \\
USA, Japanese [176] & 1971 & 100 & 24.0 \\
Japan [174] & 1974 & 1096 & 17.9 \\
USA, Japanese [108] & 1975 & 248 & 24.2 \\
Japan [108] & 1975 & 1167 & 28.4 \\
Japan [111] & 1990 & 408 & 15.7 \\
Mean & & & 22.0 \\
Weighted mean & & & 22.4
\end{tabular}

Weighted means of iodine intake categories compared by using the Chi-squared test of independence: $<100 \mu \mathrm{g} / \mathrm{L}$ vs. $100-299 \mu \mathrm{g} / \mathrm{L}(p=0.244) ; \geq 300 \mu \mathrm{g} / \mathrm{L}$ vs. $<100 \mu \mathrm{g} / \mathrm{L}$ or $100-299 \mu \mathrm{g} / \mathrm{L}$ (both, $p<0.001$ )

widely. For women, OR for a history of benign nodules/ adenomas for all thyroid cancer were 29.9 (95 \% CI: 14.5, 62.0), and for PTC and FTC were 28.9 (13.6, 61.2) and $62.3(18.9,205.8)$, respectively. The excess risk for goiter and benign nodules/adenomas was greatest within 4 years prior to thyroid cancer diagnosis, but a significantly elevated OR was still present more than 10 years before diagnosis. Case-control and cohort studies published since this analysis [15] have supported a link between goiter and/or thyroid nodules and risk of thyroid cancer [115-117].

Because iodine deficiency increases risk for goiter and thyroid nodules, these data suggest risk for thyroid cancer might be increased by iodine deficiency. However, these associations might also be explained by an increased likelihood of thyroid cancer detection in iodine deficient populations because of more frequent thyroid surgery. Also, there are other causes of goiter (e.g., thyroiditis) than iodine deficiency. In contrast to the results of the pooled analysis [15], studies in the U.S. [118] and Australia [119] did not find that thyroid cancer mortality was higher in historically goitrous regions in those two countries.

A meta-analysis of 14 cross-sectional or retrospective cohort studies [120] found the risk of thyroid cancer was significantly lower in multinodular goiter than in single nodules (OR 0.8; 95 \% CI: 0.67, 0.96). However, there was moderate inconsistency across studies $\left(\mathrm{I}^{2}=35 \%\right)$ : studies in iodine sufficient areas (U.S., Saudi Arabia, Nigeria, Croatia) found risk was lower in multinodular goiter than in single nodules (OR 0.77; 95 \% CI: 0.65, 0.92), while studies in mildly iodine deficient areas (Italy, Turkey), where multinodular goiter would be expected to be more common, found no significant association (OR 0.88; 95 \% CI: 0.68, 1.14). 


\section{Total iodine intake and thyroid cancer} Hawaii, U.S.

A case-control study in Hawaiian adults reported the association between dietary iodine intake and thyroid cancer in 191 cases (85\% PTC) and 442 controls [121]. A food frequency questionnaire was used to estimate iodine intake, but iodine content of local seafood was not available, so values were taken from other sources. Geometric mean daily iodine intake ( $\mu \mathrm{g} /$ day) was higher in female cases than in controls (394 versus 326, $p=$ 0.01 ). Iodine containing supplements contributed $\approx 7 \%$ of iodine intake. When the highest iodine intake quartile was compared to the lowest, there was a no significant increase in risk for thyroid cancer in women (OR 1.6; 95 \% CI: 0.8, 3.2) or in men (OR 1.3; 95 \% CI: 0.4, 3.7). Selection bias was not likely in this study as cases were selected from a population-based registry and controls selected through random sample of that population. However, ORs were adjusted only for age and ethnicity but not for other confounding factors.

\section{California, U.S.}

A case-control study of 608 women with thyroid cancer and 558 controls between the ages of 20 and 74 in northern California (51 \% Caucasian and $35 \%$ Asian) examined dietary iodine intake via a food frequency questionnaire and iodine levels measured in toenail clippings [115]. The main iodine sources were rice and pasta dishes and pizza (30\% of mean daily intake); milk and other dairy products (13\%); bread products (12\%); multivitamin pills (11\%); and fish/shellfish (3\%). A significant reduction in the risk of PTC was seen in the highest iodine intake quintile ( $>537 \mu \mathrm{g} /$ day) compared to the lowest (<273 $\mu \mathrm{g}$ /day) (OR 0.49; $95 \%$ CI: 0.29, 0.84), with a similar OR for Caucasian and Asian women. Iodine intake from food alone was not associated with risk, but iodine intake from supplements was; thus, the protective effect for total dietary iodine was largely attributable to the higher consumption of multivitamin pills (most brands contain $150 \mu \mathrm{g}$ of iodine) by controls. Of note, the highest quintile of dietary iodine was greater than three times the WHO RNI for iodine for this age group. There was no association between toenail iodine and PTC, but the usefulness of nail clippings as an exposure biomarker is uncertain. Although this study had a large sample size and controlled for confounding by many risk factors, there is also the possibility of selection bias as cases were found from a cancer registry but controls were obtained through random-digit dialing.

\section{New Caledonia}

Truong et al. [122] performed a countrywide case-control study of iodine intake and thyroid cancer in women on the Pacific island nation of New Caledonia. The country has a high incidence of thyroid cancer but was not exposed to iodizing radiation from past nuclear testing in the Pacific. The study included 293 cases and 354 population controls. An extensive food-frequency questionnaire was used to estimate iodine intake over the previous 5year period. Iodine intake was computed using a French food composition table, which did not have data for some local seafood, so iodine intakes may have been underestimated. Overall, total iodine intakes were low, and tertiles of intake were: $<75.0,75.0-112.6$ and $\geq 112.6 \mu \mathrm{g} /$ day, compared to the WHO RNI of $150 \mu \mathrm{g} /$ day. There was no significant association of iodine intake and thyroid cancer: comparing the upper tertile of intake versus the lower tertile, the OR was 1.13 (95\% CI: 0.68, 1.87). A high consumption of cruciferous vegetables was associated with thyroid cancer among women with iodine intakes less than $96 \mu \mathrm{g} /$ day (OR 1.86; 95 \% CI: 1.01, 3.43).

\section{French Polynesia}

French Polynesia has one of the world's highest incidence rates of thyroid cancer. A case-control study [123] included 229 cases of differentiated thyroid cancer (77\% PTC, 203 women, 26 men) matched with 371 controls. Daily dietary iodine intake was estimated from a food frequency questionnaire and was insufficient $(<150 \mu \mathrm{g} /$ day $)$ in $60 \%$ of both cases and controls. Dietary iodine intake ( $\mu \mathrm{g} /$ day) was classified as: $\leq 74$, severe or moderate deficiency; 75-149, mild deficiency, 150-299, optimal; and $\geq 300$, excess. The ORs (95\% CI) for thyroid cancer at these intakes were: $2.57(1.12,5.93) ; 1.11(0.63,1.94) ; 1.00$ (reference); $0.88(0.38,2.03)$ ( $\mathrm{p}$ for trend $=0.04)$. These results did not change after adjustment with thyroid dose from prior exposure to radioactive fallout from nuclear testing in the area. A decreased risk of thyroid cancer was observed with a higher consumption of fish and shellfish, the main sources of iodine in the diet. More frequent iodized salt consumption was associated with an increased risk of thyroid cancer, but this result was likely biased because local doctors had advised patients who had a goiter or thyroid cancer to consume iodized salt.

\section{Case-control studies: meta-analysis of total iodine intake and thyroid cancer}

We examined the association between iodine intake and thyroid cancer by performing a meta-analysis of pooled measures of effect available from the four case-control studies described above [115, 121-123]. We report the size of the effect on thyroid cancer as adjusted OR for the highest iodine intake quantile compared to the lowest quantile (Fig. 4). For each study's subgroup, we algebraically derived the logarithmic estimate for OR $(\log \mathrm{OR})$ and its standard error (SE) from the available summary statistics. We calculated the overall pooled logOR and SE using random-effects model analysis with the DerSimonian and 
Site, sex, type of thyroid cancer, summary category or subgroup (reference) ${ }^{1}$

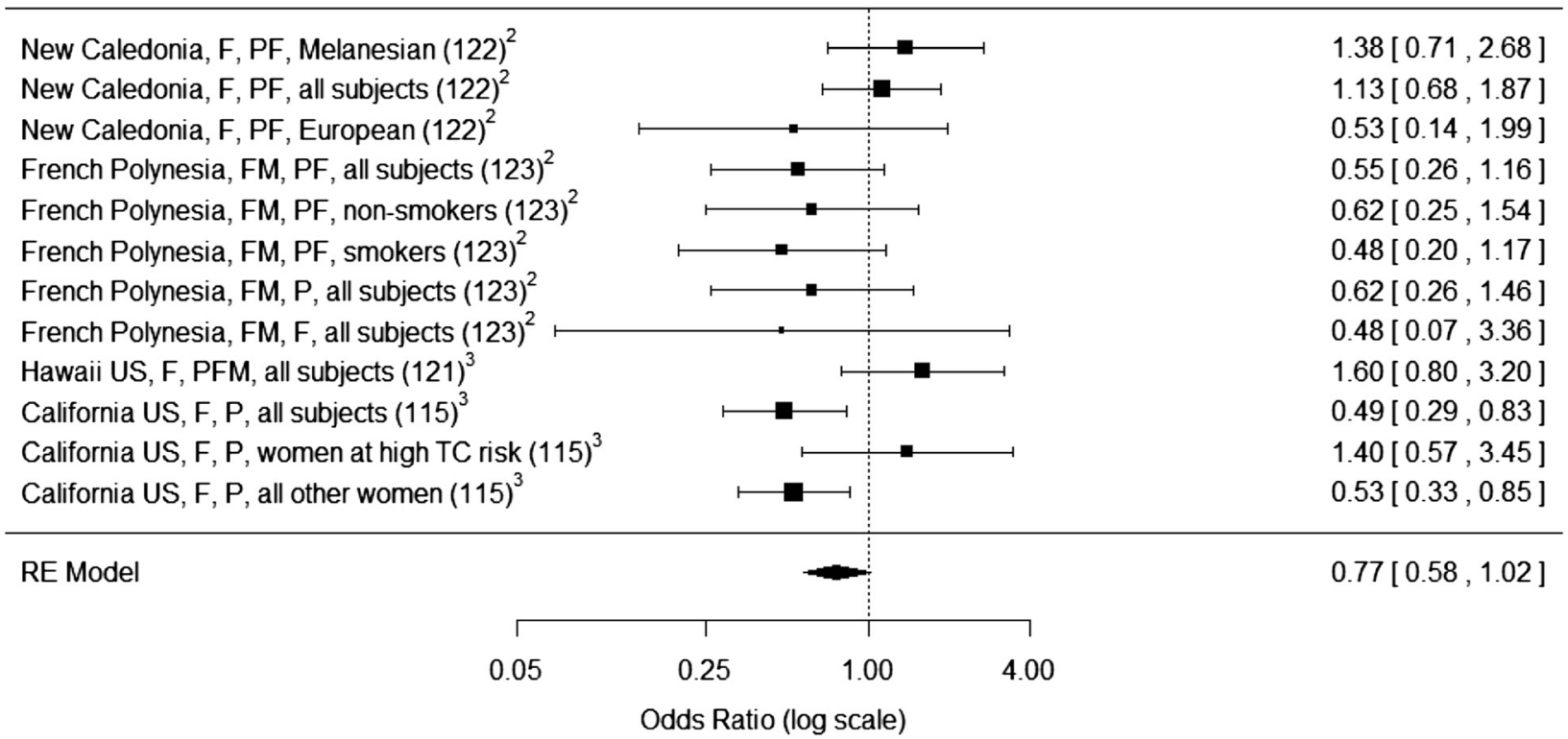

Fig. 4 Forest plot for the association between thyroid cancer risk and daily iodine intake. Effect on thyroid cancer reported as adjusted odds ratios (OR) for the highest iodine intake quantile compared to the lowest quantile. Studies are ordered ascending from lower to higher iodine intakes. Overall pooled OR 0.77 (95 \% Cl: 0.58, 1.02; $p=0.068$ ). Between-study heterogeneity: $I^{2}=42.6 \%(p=0.058)$. Publication bias: Kendall's Tau $=0.061(p=0.841)$. 'Sex: female $(F)$, male $(M)$; type of thyroid cancer: papillary (P), follicular (F), medullary (M). ${ }^{2}$ Low daily iodine intake. ${ }^{3}$ High daily iodine intake.

Laird method to estimate the between-study variance [124], and evaluated residual heterogeneity between studies using the $\mathrm{I}^{2}$ statistics. Publication bias was evaluated by visual inspection of the funnel plot of the random-effects model and by rank correlation test for funnel plot asymmetry. We performed data analysis with the $\mathrm{R}$ statistical programming environment (version 3.1.2) [125] using the metafor [126] and rmeta packages [127]. The metaanalysis indicates that the odds for thyroid cancer are $23 \%$ less in the highest quantile of iodine intake versus the lowest, although this effect was only borderline significant (OR 0.77; 95 \% CI: 0.58, 1.02; $p=0.068$ ) (Fig. 4). There was moderate evidence for between-study heterogeneity $\left(\mathrm{I}^{2}=42.6 \% ; p=0.058\right)$, but evaluation of iodine median intake as potential source of heterogeneity in a meta-regression model revealed no evidence of linearity between iodine intake and thyroid cancer $(p=0.829)$. There was no strong evidence of publication bias (Kendall's $\mathrm{Tau}=0.061 ; p=0.841$ ).

\section{Conclusions}

In summary, two of the case-control studies (Hawaii and California) were done in areas of high iodine intakes, 2-3 fold higher than recommended intakes, while the other two were done in Pacific Island populations with mildly deficient intakes. The studies in California and French Polynesia suggest higher iodine intakes may be protective against thyroid cancer, while the other two show no association. Our meta-analysis of these studies suggests a trend toward lower risk for thyroid cancer with higher iodine intake. However, in these case-control studies recall bias is always possible as cases may recall diet information differently than controls. Also, food composition data on iodine in local foods was limited and was often derived from foods from other geographic areas. Finally, the main weakness of these studies is that they did not measure UIC to assess total dietary iodine exposure and did not have data on iodine intake from iodized salt added in the household, likely an important source dietary iodine. Thus, there is a high possibility of misclassification of case of iodine exposure.

\section{Case-control and cohort studies: seafood, milk and thyroid cancer Seafood}

Fish and shellfish are important sources of dietary iodine intake in populations that consume these products regularly. Liu and Lin [128] examined the relationship between fish consumption and risk of thyroid cancer in a meta-analysis of ten cohort or case-control studies. There was a $21 \%$ decreased risk of thyroid cancer with high fish intake (OR 0.79; 95 \% CI: 0.66, 0.94). Subgroup analysis was done comparing iodine sufficient populations in Norway and the U.S. to presumed iodine deficient 
populations in Italy, Sweden and French Caledonia. In the subgroup analysis, the summary OR was 0.74 (95\% CI: $0.59,0.92)$ in the iodine deficient areas while no significant association was found in the iodine sufficient areas. Also, when the analysis was restricted to PTC, the authors found no significant association between fish intake and PTC risk. An earlier pooled analysis of case control studies published between 1980 and 1997 [129] from the United States, Japan, China and Europe found a borderline significant $12 \%$ reduction in risk of thyroid cancer with high intakes of fish (OR 0.88: 95 \% CI: 0.71, 1.1). There was a significant decrease in risk of thyroid cancer with high fish intake in regions with endemic goiter due to iodine deficiency (OR 0.65; $95 \% \mathrm{CI}$ : 0.48, 0.88 ) but not in iodine sufficient regions (OR 1.1; $95 \%$ CI: $0.85,1.5)$. The authors of these pooled analyses suggested that higher fish intakes exert a protective effect only in endemic goiter areas with suboptimal iodine intake.

\section{Milk and milk products}

In most European countries, the U.S. and Australia, population iodine intake from milk is typically greater than that from fish or seafood [130-132]. The native iodine content of milk is low, but the use of iodinecontaining supplements for cows and iodophor disinfectants during dairying and transport result in high levels in milk and milk products [131]. Cross-sectional studies in iodine sufficient Chinese adults [89] and German university students [133] found no significant association between milk intake and the prevalence of thyroid nodules detected by ultrasound. A population-based casecontrol study in Sweden and Norway [134] reported a positive association of cheese (OR 1.5; $95 \%$ CI: 1.0, 2.4) and butter (OR 1.6; $95 \%$ CI: 1.1, 2.5) and thyroid cancer risk in adults, particularly in those who had lived in an endemic goiter area and had a high intake of all milk products. In a pooled analysis of four European casecontrol studies, high consumption of milk did not increase risk of thyroid cancer, but there was a significant increase in thyroid cancer risk for high intakes of cheese and butter (OR were 1.4 and 1.8 for the highest tertiles of intake) [135]. A later pooled analysis did not find a significant relationship of milk products and thyroid cancer [136] and case-control studies in iodine sufficient Poland [137] and New Caledonia [122] found no significant association between dairy consumption and risk of thyroid cancer. In a large U.S. cohort study of adults 50-71 years of age at baseline, during 7 years of follow-up there was no association between consumption of milk products (highest quintile had 1.4-1.6 dairy food servings per $1000 \mathrm{kcal}$ ) and risk of thyroid cancer in men (relative risk (RR) 0.78; $95 \%$ CI: 0.45, 1.37) or women (RR 1.04; 95 \% CI: 0.67, 1.62) [138].

\section{lodine status and risk of thyroid cancer after radiation exposure}

External radiation to the thyroid increases risk for thyroid cancer, particularly when the radiation occurs in childhood $[9,10,139,140]$. The Chernobyl nuclear accident in 1986 exposed populations of Belarus, Ukraine, and the Russian Federation to internal radiation from radioactive iodines deposited in the thyroid, resulting in sharp increase in pediatric and adolescent thyroid cancer, mainly PTC [141]. Historically, the areas exposed to Chernobyl fallout were affected by varying degrees of iodine deficiency [142]. Chronic iodine deficiency increases thyroidal clearance of plasma iodine, increases thyroid blood flow and increases thyroid size, all of which may increase thyroid uptake of ingested radioiodines [142]. Also, iodine deficiency increases thyroid activity and thyrocyte proliferation, thereby increasing vulnerability of the thyroid to the accumulated radioiodine [54]. In rat studies, combined with a single external radiation dose of $4 \mathrm{~Gy}$, both iodine deficiency and iodine excess induced thyroid carcinomas (PTC and FTC) in $50-80 \%$ of animals, while iodine sufficient animals did not develop thyroid carcinomas (Fig. 1b) [36].

Thus, many experts predicted the risk of radiationrelated thyroid cancer after Chernobyl would be higher in more iodine deficient areas, and a number of studies have tested this hypothesis [143-146]. However, at the time of the accident, there had been no recent assessment of iodine status of the populations in the most exposed areas, so it is difficult to know with certainty which of the exposed populations were more iodine deficient when the accident occurred. Therefore, a variety of surrogates have been used to categorize iodine status at the time of exposure, such as soil iodine concentrations [144], residence in a rural versus urban area [144] or measures of iodine status more a decade after the accident $[143,145,146]$.

Shakhtarin et al. [143] investigated a population-based sample of 3070 individuals (2590 aged 6-18 years, and 480 adults) from 75 villages in the most highly contaminated regions of the Bryansk Oblast of Russia, a region that was historically an area of endemic goiter. UIC was measured in the participants in 1996 (a decade after the accident) and the median UIC was determined for each village and used to divide the study area into four zones, as follows: median UIC $\geq 100$; 75-99; 50-74; or $<50 \mu \mathrm{g} / \mathrm{L}$. Thirty four cases of thyroid cancer were identified in those born in 1968-1986 who lived in the study area at the time of the accident in 1986 (20 in females and 14 in males, median age 16 years). The excess relative risk (ERR) of thyroid cancer was directly associated with increasing thyroid radiation dose and indirectly associated with median UIC. There was a significant combined effect of radiation exposure and iodine deficiency: at 1 Gy of exposure, the 
ERR in regions with a median UIC $<50 \mu \mathrm{g} / \mathrm{L}$ (moderate iodine deficiency) was nearly two times that in areas of where the median UIC was $\geq 100 \mu \mathrm{g} / \mathrm{L}$ (iodine sufficiency).

Cardis et al. [144] performed a population-based casecontrol study of thyroid cancer in Belarus and Russia; cases were 276 thyroid cancers and controls were 1300 matched subjects below age 15 years at the time of the accident. Based on geologic maps of soil type in the affected areas, the authors estimated soil iodine concentration in rural settlements at the time of the Chernobyl accident and used these as a surrogate marker for iodine status, while classifying urban populations as iodine sufficient because it was assumed they were obtaining iodine sufficient foods from outside the local area. For subjects residing in areas with the lowest tertile of estimated soil iodine, the odds of developing thyroid cancer after a 1-Gy exposure were 3.2 (95 \% CI: 1.9, 5.5) times higher than that for subjects living in areas of greater soil iodine. However, most of the areas studied had iodine deficient soils, so the comparison group (the higher two tertiles of soil iodine) was likely not iodine sufficient.

Tronko et al. [145] performed a prospective cohort study in 12 to 33 year-olds in the Ukraine who had been exposed to radiation from the Chernobyl accident during childhood. The authors assessed iodine status in subjects by goiter palpation and spot UICs more than a decade after the accident, in 1998-2000, when the median UIC was $\approx 50 \mu \mathrm{g} / \mathrm{L}$. The study found no significant relationship between UIC and risk of thyroid cancer. A history of goiter was associated with a nonsignificant doubling in risk of thyroid cancer (OR 2.19; 95 \% CI: 0.96, 5.03), but the study had limited statistical power due to a small number of cancer cases $(n=45)$. The later measurements of UIC and goiter may not reflect iodine status at the time of the accident because of changes in dietary habits and food distribution in the intervening period.

Zablotska et al. [146] screened nearly 12,000 individuals in Belarus aged 18 years or younger at the time of the Chernobyl accident. Past iodine deficiency was estimated by using self-reported history of diffuse and nodular goiter, as well as diffuse goiter and UICs measured during screening in 1996 through 2004. After adjustment for radiation dose, the prevalence rate for thyroid cancer was significantly higher for those with a self-reported history of nodular (OR 23.21) or diffuse goiter (OR 5.15), or with nodular or diffuse goiter diagnosed at screening (ORs 19.79 and 3.16). But UIC at screening was not associated with thyroid cancer; there was no significant increase in risk comparing those with moderate to severe iodine deficiency (UICs $<50 \mu \mathrm{g} / \mathrm{L}$ ) to those with higher UICs. However, Belarus began salt iodization in late 2000 and iodine status has generally been adequate in the population since then, so the later
UIC measurements in this study likely differ from those at the time of the accident in 1986 [147].

\section{Conclusions}

In these studies, the reliability of the proxy measures used to define iodine status at the time of the accident is uncertain, and therefore it is difficult to draw conclusions. However, an error in classification of iodine status in these studies would likely have been random and would have biased their estimates toward the null. Despite this, 3 out of 4 studies [143, 144, 146] found that poorer iodine status in children at the time of the accident was associated with $\mathrm{a} \approx 2-3$ fold increase in risk for developing thyroid cancer.

\section{Conclusions}

The incidence of thyroid cancer has been rising steadily over the past few decades in most countries [1]. Much of this increase is due to increased case finding because of improved screening and diagnosis methods, but there may also be a true increase, so it is important to clarify the role of suspected risk factors, including iodine intake. Population iodine intakes can vary up to 50 fold -from intakes less than $20 \mu \mathrm{g} / \mathrm{d}$ in areas of severe deficiency, to more than $1000 \mu \mathrm{g} / \mathrm{d}$ in areas with high iodine levels in drinking water or from intake of iodine-rich seaweed. Moreover, iodine intakes are shifting in many countries: they are increasing in some countries as iodized salt is introduced to correct iodine deficiency, while others report falling intakes, due to changes in dietary habits and patterns of iodine use by the food and dairy industry. It is well known that even small variations in population iodine intake are a determinant of benign thyroid disorders [16]. So why does the role of iodine intake in thyroid cancer remains uncertain, despite decades of study?

There are many reasons. Comparison studies of thyroid cancer epidemiology in populations and geographic areas are challenging because thyroid cancer is still a relatively rare and, in most cases, indolent cancer. Thus, long study periods in large populations are needed and this increases the likelihood of bias from changes in unmeasured risk factors other than iodine intake. There is the additional large uncertainty of the lag-time between changes in iodine exposure and changes in incidence of thyroid cancer; the lag-time between increasing iodine intake and the resolution of diffuse goiter and nodules in adult populations is several decades [67]. Accurate dietary assessment of iodine intake is notoriously difficult because discretionary use of household iodized salt and use of iodized salt in processed foods is difficult to quantify [24]. Finally, all of these difficulties are compounded by the current lack of an individual biomarker of iodine status: applying a population indicator such as the median 
UIC to classify individual risk for thyroid cancer likely introduces substantial classification bias.

Animal studies indicate iodine deficiency is a weak initiator but a strong promoter of thyroid cancer, mainly of the follicular type. Less convincing evidence suggests iodine excess may be a weak promoter of thyroid cancer. The proposed mechanism for the effects of iodine deficiency -chronic elevation of TSH stimulates thyrocyte proliferation and increases the likelihood of mutagenesis- is plausible and supported by animal studies. However, TSH is not elevated in animals fed diets with excessive iodine, so the mechanism for the effects of excess iodine is unknown. Limited data from thyroid cell cultures suggest exposure to high amounts of iodine reduces RET/PTC3 and BRAF oncogene activation, but the relevance of these studies is uncertain because the iodine concentrations used were far above physiologic levels in the thyroid. A single human study found the RAS oncogene mutation rate was higher in FTC cases from an iodine deficient area, and in the two human studies investigating the BRAF mutation in PTC, one found no increased occurrence in cases from an iodine deficient area population while another found an increased occurrence in an iodine excess area. More wellcontrolled studies are needed to clarify the potential links between iodine intake and molecular alterations such as mutations of the BRAF and RAS genes and $B R A F$ and $R E T$ rearrangements in thyroid cancer.

The overall incidence of thyroid cancer in populations does not appear to be influenced by the usual range of iodine intakes from dietary sources. The evidence is more convincing that increases in iodine intake may change the distribution of subtypes of thyroid cancer, particularly important are the data from countries before and after iodine prophylaxis done before the recent increases in diagnostic intensity (Table 3). These data are consistent in showing a higher percentage of the more-aggressive ATC and FTC in iodine deficient areas, whereas PTC seems to be more common in areas with high iodine intakes. Thus, by reducing FTC, and particularly ATC, iodized salt programs may be contributing to the decrease in thyroid cancer mortality seen in many countries; the data in Fig. 3 suggest this benefit may be strongest in women. However, firm conclusions cannot be made because of unmeasured covariates that may have changed over time along with iodine status, such as standards of medical care, environmental exposures, and histological classification.

Over the past 2 to 3 decades, there is clear temporal relationship in many countries between introduction of iodized salt and an increase in incidence of PTC. However, at the same time, several countries that have stable or decreasing iodine intakes, including Australia, the U.S. and Switzerland (Fig. 2), have also experienced an increase in PTC. Although a causal role of iodine intake in the etiology of PTC cannot be ruled out, a more likely explanation for the increasing incidence of PTC worldwide is the introduction and wider use of improved thyroid diagnostics. Compounding this, in areas without iodine deficiency and hence less goiter, individuals are more likely to notice a small change in their thyroid and go for medical examination. Thus, we may never have a clear answer to the question of whether changes in iodine intake contribute to PTC. Of note, autopsy studies of OTC are not confounded by changes in diagnostic and treatment, and they suggest that papillary microcarcinomas are actually less common in areas (outside of Japan) with high iodine intakes (Table 3).

The available data from case-control studies suggest higher iodine intakes and higher intakes of fish and seafood, particularly in iodine deficient populations, are linked to a small reduction in risk of thyroid cancer. However, the associations are weak and inconsistent and none of these studies were done in populations with clear iodine deficiency or excess. Future research should emphasize the collection of prospective data from large cohorts where total iodine exposure is assessed by measurement of repeated UICs, together with other iodine status biomarkers, such as serum thyroglobulin.

Overall, the available evidence suggests iodine deficiency is a risk factor for thyroid cancer, and that it particularly increases risk for FTC and possibly, ATC. This conclusion is based on: a) consistent data showing an increase in thyroid cancer (mainly follicular) in iodine deficient animals; b) a plausible mechanism (chronic TSH stimulation induced by iodine deficiency); c) consistent data from before and after studies of iodine prophylaxis showing a decrease in the percentage of thyroid cancer that is FTC and ATC; d) the indirect association between iodine intake and thyroid cancer mortality in the decade from 2000 to 2010; e) the autopsy studies of OTC showing microcarcinoma rates with lower iodine intakes; $f$ ) and the case control studies showing a trend toward lower risk for thyroid cancer with higher fish and total iodine intakes.

\section{Additional file}

Additional file 1: Table S1. National age-adjusted death rates from thyroid cancer and median urinary iodine concentration in years 2000-2010.

\section{Abbreviations}

ATC: Anaplastic thyroid cancer; BHP: N-nitrosobis(2-hydroxypropyl)amine; Cl: Confidence intervals; TC: Thyroid cancer; DHPN: N-bis(2-hydroxypropyl)nitrosamine; ERR: Excess relative risk; FTC: Follicular thyroid cancer; ICCIDD: International Council for the Control of lodine Deficiency Disorders (now lodine Global Network); MAPK: mitogen-activated protein kinase; NHANES: National Health and Nutrition Examination Surveys;

NMU: N-nitrosomethylurea; OR: Odds ratio; OTC: Occult thyroid carcinomas; PTC: Papillary thyroid cancer; RNI: Recommended nutrient intake; RR: Relative risk; SE: Standard error; TSH: Thyroid-stimulating hormone; UIC: Urinary iodine concentration; UNICEF: United Nations Children's Fund; WHO: World Health Organization. 


\section{Competing interests}

The authors declare that they have no competing interests.

\section{Authors' contributions}

MBZ wrote the draft of the manuscript. VG performed statistical analysis. Both authors read and approved the final manuscript.

\section{Acknowledgements}

The writing of this review was supported by a grant from the ETH Zürich, Switzerland.

\section{Author details Switzerland. \\ Received: 27 May 2015 Accepted: 8 June 2015 \\ Published online: 18 June 2015}

${ }^{1}$ Laboratory of Human Nutrition, Department of Health Sciences and Technology, ETH Zürich, Schmelzbergstrasse 7, LFV D21, CH-8092 Zürich, Switzerland. 'Laboratory of Human Nutrition, Department of Health Sciences and Technology, ETH Zürich, Schmelzbergstrasse 7, LFV E14, CH-8092 Zürich,

\section{References}

1. La Vecchia C, Malvezzi M, Bosetti C, Garavello W, Bertuccio P, Levi F, et al. Thyroid cancer mortality and incidence: a global overview. Int J Cancer. 2015;136:2187-95.

2. Rahib L, Smith BD, Aizenberg R, Rosenzweig AB, Fleshman JM, Matrisian LM. Projecting cancer incidence and deaths to 2030: the unexpected burden of thyroid, liver, and pancreas cancers in the United States. Cancer Res. 2014;74:2913-21.

3. Chen AY, Jemal A, Ward EM. Increasing incidence of differentiated thyroid cancer in the United States, 1988-2005. Cancer. 2009;115:3801-7.

4. Enewold L, Zhu K, Ron E, Marrogi AJ, Stojadinovic A, Peoples GE, et al. Rising thyroid cancer incidence in the United States by demographic and tumor characteristics, 1980-2005. Cancer Epidemiol Biomarkers Prev. 2009;18:784-91.

5. Morris LGT, Sikora AG, Tosteson TD, Davies $L$. The increasing incidence of thyroid cancer: the influence of access to care. Thyroid. 2013;23:886-92.

6. Udelsman $R$, Zhang $Y$. The epidemic of thyroid cancer in the United States: the role of endocrinologists and ultrasounds. Thyroid. 2014;24:472-9.

7. Ahn HS, Kim HJ, Welch HG. Korea's thyroid-cancer "epidemic" - screening and overdiagnosis. N Engl J Med. 2014;371:1765-7.

8. Bard D, Verger P, Hubert P. Chernobyl, 10 years after: health consequences. Epidemiol Rev. 1997;19:187-204.

9. Mazonakis M, Tzedakis A, Damilakis J, Gourtsoyiannis N. Thyroid dose from common head and neck CT examinations in children: is there an excess risk for thyroid cancer induction? Eur Radiol. 2007;17:1352-7.

10. Bounacer A, Wicker R, Caillou B, Cailleux AF, Sarasin A, Schlumberger M, et al. High prevalence of activating ret proto-oncogene rearrangements, in thyroid tumors from patients who had received external radiation. Oncogene. 1997;15:1263-73.

11. Renehan AG, Tyson M, Egger M, Heller RF, Zwahlen M. Body-mass index and incidence of cancer: a systematic review and meta-analysis of prospective observational studies. Lancet. 2008;371:569-78.

12. Rinaldi S, Lise M, Clavel-Chapelon F, Boutron-Ruault MC, Guillas G, Overvad $K$, et al. Body size and risk of differentiated thyroid carcinomas: findings from the EPIC study. Int J Cancer. 2012;131:E1004-14

13. Hallgren S, Darnerud PO. Polybrominated diphenyl ethers (PBDEs), polychlorinated biphenyls (PCBs) and chlorinated paraffins (CPS) in rats testing interactions and mechanisms for thyroid hormone effects. Toxicology. 2002;177:227-43.

14. Zhang Y, Guo GL, Han X, Zhu C, Kilfoy BA, Zhu Y, et al. Do Polybrominated Diphenyl Ethers (PBDEs) Increase the Risk of Thyroid Cancer? Biosci Hypotheses. 2008;1:195-9.

15. Franceschi S, Preston-Martin S, Dal Maso L, Negri E, La Vecchia C, Mack WJ, et al. A pooled analysis of case-control studies of thyroid cancer. IV. Benign thyroid diseases. Cancer Causes Control. 1999;10:583-95.

16. Zimmermann MB, Boelaert K. lodine deficiency and thyroid disorders. Lancet Diabetes Endocrinol. 2015;3:286-95.

17. Wegelin C. Malignant disease of the thyroid gland and its relation to goiter in man and animals. Cancer Rev. 1928:3:297.
18. Global lodine Nutrition Scorecard 2014. Available at: http://www.ign.org/ cm_data/Scorecard_IGN_website_02_03_2015.pdf. Accessed 2 Mar 2015.

19. Carle A, Krejbjerg A, Laurberg P. Epidemiology of nodular goitre. Influence of iodine intake. Best Pract Res Clin Endocrinol Metab. 2014;28:465-79.

20. Cole WH, Majarakis JD, Slaughter DP. Incidence of carcinoma of the thyroid in nodular goiter. J Clin Endocrinol Metab. 1949;9:1007-11.

21. Feldt-Rasmussen U. lodine and cancer. Thyroid. 2001;11:483-6.

22. Williams ED. Dietary iodide and thyroid cancer. In: Hall R, Köbberling J, editors. Thyroid disorders associated with iodine deficiency and excess. New York: Raven; 1985.

23. World Health Organization, United Nations Children's Fund, International Council for the Control of lodine Deficiency Disorders. Assessment of iodine deficiency disorders and monitoring their elimination. A guide for programme managers. 3rd ed. Geneva: World Health Organization; 2007.

24. Zimmermann MB, Andersson M. Assessment of iodine nutrition in populations: past, present, and future. Nutr Rev. 2012;70:553-70.

25. Axelrad AA, Leblond CP. Induction of thyroid tumors in rats by a low iodine diet. Cancer. 1955;8:339-67.

26. Isler $\mathrm{H}$, Leblond CP, Axelrad AA. Influence of age and of iodine intake on the production of thyroid tumors in the rat. J Natl Cancer Inst. 1958;21:1065-81

27. Isler $\mathrm{H}$. Effect of iodine on thyroid tumors induced in the rat by a lowiodine diet. J Natl Cancer Inst. 1959;23:675-93.

28. Schaller Jr RT, Stevenson JK. Development of carcinoma of the thyroid in iodine-deficient mice. Cancer. 1966;19:1063-80.

29. Fortner JG, George PA, Sternberg SS. The development of thyroid cancer and other abnormalities in Syrian hamsters maintained on an iodine deficient diet. Surg Forum. 1958;9:646-50.

30. Correa P, Welsh RA. The effect of excessive iodine intake on the thyroid gland of the rat. Arch Pathol. 1960;70:247-51.

31. Ohshima M, Ward JM. Promotion of N-Methyl-N-Nitrosourea-Induced Thyroid-Tumors by lodine Deficiency in F344 Ncr Rats. J Natl Cancer I. 1984;73:289-96.

32. Ohshima M, Ward JM. Dietary iodine deficiency as a tumor promoter and carcinogen in male F344/Ncr rats. Cancer Res. 1986;46:877-83.

33. Kanno J, Onodera H, Furuta K, Maekawa A, Kasuga T, Hayashi Y. Tumorpromoting effects of both iodine deficiency and iodine excess in the ratthyroid. Toxicol Pathol. 1992;20:226-35.

34. Yamashita H, Noguchi S, Murakami N, Kato R, Adachi M, Inoue S, et al. Effects of dietary iodine on chemical induction of thyroid-carcinoma. Acta Pathol Japon. 1990;40:705-12.

35. Cho YM, Imai T, Hasumura M, Hirose M. Lack of enhancement of susceptibility to mammary and thyroid carcinogenesis in rats exposed to DMBA and DHPN following prepubertal iodine deficiency. Cancer Sci. 2006;97:1031-6

36. Boltze C, Brabant G, Dralle H, Gerlach R, Roessner A, Hoang-Vu C. Radiationinduced thyroid carcinogenesis as a function of time and dietary iodine supply: An in vivo model of tumorigenesis in the rat. Endocrinology. 2002;143:2584-92.

37. al-Saadi AA, Beierwaltes WH. Chromosomal changes in rat thyroid cells during iodine depletion and repletion. Cancer Res. 1966;26:676-88.

38. Riesco G, Taurog A, Larsen R, Krulich L. Acute and chronic responses to iodine deficiency in rats. Endocrinology. 1977;100:303-13.

39. Hill RN, Erdreich LS, Paynter OE, Roberts PA, Rosenthal SL, Wilkinson CF. Thyroid follicular cell carcinogenesis. Fundam Appl Toxicol. 1989;12:629-97.

40. Ward JM, Ohshima M. The role of iodine in carcinogenesis. Adv Exp Med Biol. 1986;206:529-42.

41. Kaplan MM. Progress in Thyroid-Cancer. Endocrin Metab Clin. 1990;19:469-78.

42. Doniach I, Williams ED. The development of thyroid and pituitary tumours in the rat two years after partial thyroidectomy. Br J Cancer. 1962;16:222-31.

43. Purves HD, Griesbach WE. Studies on experimental goitre; thyroid tumours in rats treated with thiourea. Br J Exp Pathol. 1947;28:46-53.

44. Wynford-Thomas D, Stringer BMJ, Williams ED. Desensitization of rat-thyroid to the growth-stimulating action of Tsh during prolonged goitrogen administration - persistence of refractoriness following withdrawal of stimulation. Acta Endocrinol (Copenh). 1982;101:562-9.

45. Uyttersprot N, Pelgrims N, Carrasco N, Gervy C, Maenhaut C, Dumont JE, et al. Moderate doses of iodide in vivo inhibit cell proliferation and the expression of thyroperoxidase and Na+/l- symporter mRNAs in dog thyroid. Mol Cell Endocrinol. 1997;131:195-203.

46. Eng PHK, Cardona GR, Fang SL, Previti M, Alex S, Carrasco N, et al. Escape from the acute Wolff-Chaikoff effect is associated with a decrease in thyroid 
sodium/iodide symporter messenger ribonucleic acid and protein. Endocrinology. 1999;140:3404-10.

47. Krohn K, Maier J, Paschke R. Mechanisms of Disease: hydrogen peroxide, DNA damage and mutagenesis in the development of thyroid tumors. Nat Clin Pract Endoc. 2007;3:713-20.

48. Maier J, van Steeg H, van Oostrom C, Paschke R, Weiss RE, Krohn K. lodine deficiency activates antioxidant genes and causes DNA damage in the thyroid gland of rats and mice. Biochim Biophys Acta. 2007;1773:990-9.

49. Vitale M, Di Matola T, D'Ascoli F, Salzano S, Bogazzi F, Fenzi G, et al. lodide excess induces apoptosis in thyroid cells through a p53-independent mechanism involving oxidative stress. Endocrinology. 2000;141:598-605.

50. Cardoso LC, Martins DC, Figueiredo MD, Rosenthal D, Vaisman M, Violante $\mathrm{AH}$, et al. $\mathrm{Ca}(2+) /$ nicotinamide adenine dinucleotide phosphate-dependent $\mathrm{H}(2) \mathrm{O}(2)$ generation is inhibited by iodide in human thyroids. J Clin Endocrinol Metab. 2001;86:4339-43.

51. Langer R, Burzler C, Bechtner G, Gartner R. Influence of iodide and iodolactones on thyroid apoptosis. Evidence that apoptosis induced by iodide is mediated by iodolactones in intact porcine thyroid follicles. Exp Clin Endocr Diab. 2003;111:325-9.

52. Gartner R, Rank P, Ander B. The role of iodine and delta-iodolactone in growth and apoptosis of malignant thyroid epithelial cells and breast cancer cells. Hormones (Athens). 2010;9:60-6.

53. Kimura ET, Nikiforova MN, Zhu ZW, Knauf JA, Nikiforov YE, Fagin JA. High prevalence of BRAF mutations in thyroid cancer: genetic evidence for constitutive activation of the RET/PTC-RAS-BRAF signaling pathway in papillary thyroid carcinoma. Cancer Res. 2003;63:1454-7.

54. Liu XH, Chen GG, Vlantis AC, van Hasselt CA. lodine mediated mechanisms and thyroid carcinoma. Crit Rev Cl Lab Sci. 2009;46:302-18.

55. Frasca F, Nucera C, Pellegriti G, Gangemi P, Attard M, Stella M, et al. BRAF(V600E) mutation and the biology of papillary thyroid cancer. Endocr Relat Cancer. 2008;15:191-205.

56. Guan H, Ji M, Bao R, Yu H, Wang Y, Hou P, et al. Association of high iodine intake with the T1799A BRAF mutation in papillary thyroid cancer. J Clin Endocrinol Metab. 2009;94:1612-7.

57. Fuziwara CS, Kimura ET. High iodine blocks a Notch/miR-19 loop activated by the BRAF(V600E) oncoprotein and restores the response to TGFbeta in thyroid follicular cells. Thyroid. 2014;24:453-62.

58. Shi YF, Zou MJ, Schmidt H, Juhasz F, Stensky V, Robb D, et al. High-rates of Ras Codon-61 mutation in thyroid-tumors in an iodide-deficient area. Cancer Res. 1991;51:2690-3.

59. Fiore AP, Fuziwara CS, Kimura ET. High iodine concentration attenuates RET/ PTC3 oncogene activation in thyroid follicular cells. Thyroid. 2009:19:1249-56.

60. Xiang J, Wang XM, Wang ZY, Wu Y, Li DS, Shen Q, et al. Effect of different iodine concentrations on well-differentiated thyroid cancer cell behavior and its inner mechanism. Cell Biochem Biophys. 2015;71:299-305.

61. Langsteger W, Koltringer P, Wolf G, Dominik K, Buchinger W, Binter G, et al The impact of geographical, clinical, dietary and radiation-induced features in epidemiology of thyroid cancer. Eur J Cancer. 1993;29A:1547-53.

62. Saxen E, Franssila K, Bjarnason O, Normann T, Ringertz N. Observer variation in histologic classification of thyroid cancer. Acta Pathol Microbiol Scand A. 1978:86A:483-6

63. Hedinger CE, Sobin LH. Histological Typing of Thyroid Tumours. Geneva: World Health Organization (International Histological Classification of Tumours, No 11); 1974

64. Verkooijen HM, Fioretta G, Pache JC, Franceschi S, Raymond L, Schubert H, et al. Diagnostic changes as a reason for the increase in papillary thyroid cancer incidence in Geneva, Switzerland. Cancer Causes Control. 2003;14:13-7.

65. Walthard B. Der Gestaltwandel Der Struma Maligna Mit Bezug Auf Die Jodprophylaxe Des Kropfes. Schweiz Med Wochenschr. 1963;93:809.

66. Hofstadter F. Frequency and morphology of malignant-tumors of the thyroid before and after the introduction of iodine-prophylaxis. Virchows Arch A Pathol Anat Histol. 1980;385:263-70.

67. Bubenhofer $\mathrm{R}$, Hedinger $C$. Thyroid neoplasms before and after the prophylactic supplementation of table salt with iodine]. Schweiz Med Wochenschr. 1977;107:733-41.

68. Leenhardt L, Bernier MO, Boin-Pineau MH, Conte Devolx B, Marechaud R, Niccoli-Sire $P$, et al. Advances in diagnostic practices affect thyroid cancer incidence in France. Eur J Endocrinol. 2004;150:133-9.

69. Cl5plus: Cancer Incidence In Five Continents Time Trends. Available at: http://ci5.iarc.fr/Cl5plus/Pages/online.aspx. Accessed 11 Dec 2014.
70. Hollowell JG, Staehling NW, Hannon WH, Flanders DW, Gunter EW, Maberly GF, et al. lodine nutrition in the United States. Trends and public health implications: Iodine excretion data from National Health and Nutrition Examination Surveys I and III (1971-1974 and 1988-1994). J Clin Endocrinol Metab. 1998:83:3401-8

71. Pan Y, Caldwell KL, Li Y, Caudill SP, Mortensen ME, Makhmudov A, et al. Smoothed urinary iodine percentiles for the US population and pregnant women: National Health and Nutrition examination survey, 2001-2010. Eur Thyroid J. 2013;2:127-34.

72. Lubitz CC, Kong CY, McMahon PM, Daniels GH, Chen YF, Economopoulos $K P$, et al. Annual financial impact of well-differentiated thyroid cancer care in the United States. Cancer. 2014;120:1345-52.

73. Pettersson B, Coleman MP, Ron E, Adami HO. lodine supplementation in Sweden and regional trends in thyroid cancer incidence by histopathologic type. Int J Cancer. 1996;65:13-9.

74. Rasmussen LB, Jorgensen T, Perrild H, Knudsen N, Krejbjerg A, Laurberg P, et al. Mandatory iodine fortification of bread and salt increases iodine excretion in adults in Denmark - a 11-year follow-up study. Clin Nutr. 2014;33:1033-40

75. Blomberg M, Feldt-Rasmussen U, Andersen KK, Kjaer SK. Thyroid cancer in Denmark 1943-2008, before and after iodine supplementation. Int J Cancer. 2012;131:2360-6.

76. Knudsen N, Bulow I, Jorgensen T, Laurberg P, Ovesen L, Perrild H. Goitre prevalence and thyroid abnormalities at ultrasonography: a comparative epidemiological study in two regions with slightly different iodine status. Clin Endocrinol (Oxf). 2000;53:479-85.

77. Sehestedt $\mathrm{T}$, Knudsen $\mathrm{N}$, Perrild $\mathrm{H}$, Johansen $\mathrm{C}$. lodine intake and incidence of thyroid cancer in Denmark. Clin Endocrinol (Oxf). 2006;65:229-33.

78. Netea-Maier RT, Aben KKH, Casparie MK, den Heijer M, Grefte JMM, Slootweg $\mathrm{P}$, et al. Trends in incidence and mortality of thyroid carcinoma in The Netherlands between 1989 and 2003: correlation with thyroid fineneedle aspiration cytology and thyroid surgery. Int J Cancer. 2008;123:1681-4

79. Williams ED, Doniach I, Bjarnason O, Michie W. Thyroid Cancer in an lodide Rich Area - Histopathological Study. Cancer. 1977;39:215-22.

80. Radespiel-Troger M, Batzler WU, Holleczek B, Luttmann S, Pritzkuleit R, Stabenow R, et al. Im Namen der Gesellschaft der epidemiologischen Krebsregister in Deutschland e $\mathrm{V}$ [Rising incidence of papillary thyroid carcinoma in Germany]. Bundesgesundheitsbl Gesundheitsforsch Gesundheitsschutz. 2014:57:84-92.

81. Lise M, Franceschi S, Buzzoni C, Zambon P, Falcini F, Crocetti E, et al. Changes in the incidence of thyroid cancer between 1991 and 2005 in Italy: a geographical analysis. Thyroid. 2012;22:27-34.

82. Belfiore A, La Rosa GL, La Porta GA, Giuffrida D, Milazzo G, Lupo L, et al. Cancer risk in patients with cold thyroid nodules: relevance of iodine intake, sex, age, and multinodularity. Am J Med. 1992;93:363-9.

83. Ilias I, Alevizaki M, Lakka-Papadodima E, Koutras DA. Differentiated thyroid cancer in Greece: 1963-2000. Relation to demographic and environmental factors. Hormones (Athens). 2002;1:174-8.

84. Rego-Iraeta A, Perez-Mendez LF, Mantinan B, Garcia-Mayor RV. Time trends for thyroid cancer in northwestern Spain: true rise in the incidence of micro and larger forms of papillary thyroid carcinoma. Thyroid. 2009;19:333-40.

85. Wang Y, Wang W. Increasing Incidence of Thyroid Cancer in Shanghai, China, 1983-2007. Asia Pac J Public Health. 2015;27:NP223-9.

86. Dong W, Zhang H, Zhang P, Li X, He L, Wang Z, et al. The changing incidence of thyroid carcinoma in Shenyang, China before and after universal salt iodization. Med Sci Monit. 2013;19:49-53.

87. Teng WP, Shan ZY, Teng XC, Guan HX, Li YH, Teng D, et al. Effect of iodine intake on thyroid diseases in China. New Eng J Med. 2006;354:2783-93.

88. Zhu W, Liu X, Hu X, Zhou S, Wang Y, Zhang Y. Investigation on the iodine nutritional status and the prevalence of thyroid carcinoma in Zhoushan Archipelago residents. Wei Sheng Yan Jiu. 2012:41:79-82.

89. Chen ZX, Xu WM, Huang YM, Jin X, Deng J, Zhu SJ, et al. Associations of noniodized salt and thyroid nodule among the Chinese population: a large cross-sectional study. Am J Clin Nutr. 2013;98:684-92.

90. Wong EY, Ray R, Gao DL, Wernli KJ, Li W, Fitzgibbons ED, et al. Reproductive history, occupational exposures, and thyroid cancer risk among women textile workers in Shanghai, China. Int Arch Occ Env Hea. 2006;79:251-8.

91. Yin JH, Wang CC, Shao Q, Qu DH, Song ZY, Shan PF, Zhang T, Xu J, Liang Q, Zhang SZ, Huang J. Relationship between the Prevalence of Thyroid Nodules and Metabolic Syndrome in the lodine-Adequate Area of 
Hangzhou, China: A Cross-Sectional and Cohort Study. Int J Endocrinol. 2014.

92. Burgess JR, Dwyer T, McArdle K, Tucker P, Shugg D. The changing incidence and spectrum of thyroid carcinoma in Tasmania (1978-1998) during a transition from iodine sufficiency to iodine deficiency. J Clin Endocrinol Metab. 2000;85:1513-7.

93. Burgess JR. Temporal trends for thyroid carcinoma in Australia: an increasing incidence of papillary thyroid carcinoma (1982-1997). Thyroid. 2002;12:141-9.

94. Li M, Eastman CJ, Waite KV, Ma G, Zacharin MR, Topliss DJ, et al. Are Australian children iodine deficient? Results of the Australian National lodine Nutrition Study. Med J Aust. 2006;184:165-9.

95. Harach HR, Ceballos GA. Thyroid cancer, thyroiditis and dietary iodine: a review based on the Salta, Argentina Model. Endocr Pathol. 2008;19:209-20.

96. Chiacchio S, Lorenzoni A, Boni G, Rubello D, Elisei R, Mariani G. Anaplastic thyroid cancer: prevalence, diagnosis and treatment. Minerva Endocrinol. 2008:33:341-57.

97. Besic N, Hocevar M, Zgajnar J. Lower incidence of anaplastic carcinoma after higher iodination of salt in Slovenia. Thyroid. 2010;20:623-6.

98. Bacher-Stier C, Riccabona G, Totsch M, Kemmler G, Oberaigner W, Moncayo R. Incidence and clinical characteristics of thyroid carcinoma after iodine prophylaxis in an endemic goiter country. Thyroid. 1997;7:733-41.

99. Farahati J, Geling M, Mader U, Mortl M, Luster M, Muller JG, et al. Changing trends of incidence and prognosis of thyroid carcinoma in lower Franconia, Germany, from 1981-1995. Thyroid. 2004;14:141-7.

100. Ceresini G, Corcione L, Michiara M, Sgargi P, Teresi G, Gilli A, et al. Thyroid cancer incidence by histological type and related variants in a mildly iodinedeficient area of Northern Italy, 1998 to 2009. Cancer. 2012;118:5473-80.

101. Guberan E. [Mortality trends in Switzerland. 3. Tumors: 1921-1978]. Schweiz Med Wochenschr Suppl. 1980;Suppl 11:1-18.

102. Reynolds RM, Weir J, Stockton DL, Brewster DH, Sandeep TC, Strachan MW. Changing trends in incidence and mortality of thyroid cancer in Scotland. Clin Endocrinol (Oxf). 2005;62:156-62.

103. Harach HR, Galindez M, Campero M, Ceballos GA. Undifferentiated (Anaplastic) Thyroid Carcinoma and lodine Intake in Salta, Argentina. Endocr Pathol. 2013;24:125-31.

104. Carcangiu ML, Steeper T, Zampi G, Rosai J. Anaplastic thyroid carcinoma. A study of 70 cases. Am J Clin Pathol. 1985;83:135-58.

105. Smallridge RC, Copland JA. Anaplastic thyroid carcinoma: pathogenesis and emerging therapies. Clin Oncol. 2010;22:486-97.

106. World Health Organization Statistical Information System (WHOSIS). WHO Mortality Database. Geneva: World Health Organization. Available at: http://apps.who.int/healthinfo/statistics/mortality/whodpms/.

107. WHO Vitamin and Mineral Nutrition Information System (VMNIS). Database on lodine Deficiency. Available at: http://www.who.int/vmnis/database/ iodine/en/. Accessed 11 Dec 2014.

108. Fukunaga FH, Yatani R. Geographic pathology of occult thyroid carcinomas. Cancer. 1975;36:1095-9.

109. Kovacs GL, Gonda G, Vadasz G, Ludmany E, Uhrin K, Gorombey Z, et al. Epidemiology of thyroid microcarcinoma found in autopsy series conducted in areas of different iodine intake. Thyroid. 2005;15:152-7.

110. Neuhold N, Kaiser H, Kaserer K. Latent carcinoma of the thyroid in Austria: a systematic autopsy study. Endocr Pathol. 2001;12:23-31.

111. Yamamoto $Y$, Maeda T, Izumi K, Otsuka H. Occult papillary carcinoma of the thyroid - a study of 408 autopsy cases. Cancer. 1990;65:1173-9.

112. Harach HR, Franssila KO, Wasenius VM. Occult papillary carcinoma of the thyroid - a normal finding in Finland - a systematic autopsy study. Cancer. 1985;56:531-8

113. Derwahl M, Studer H. Nodular goiter and goiter nodules: Where iodine deficiency falls short of explaining the facts. Exp Clin Endocr Diab. 2001;109:250-60

114. Krohn K, Fuhrer D, Bayer Y, Eszlinger M, Brauer V, Neumann S, et al. Molecular pathogenesis of euthyroid and toxic multinodular goiter. Endocr Rev. 2005;26:504-24.

115. Horn-Ross PL, Morris JS, Lee M, West DW, Whittemore AS, McDougall IR, et al. lodine and thyroid cancer risk among women in a multiethnic population: the Bay Area Thyroid Cancer Study. Cancer Epidemiol Biomarkers Prev. 2001;10:979-85.

116. Memon A, Varghese A, Suresh A. Benign thyroid disease and dietary factors in thyroid cancer: a case-control study in Kuwait. Br J Cancer. 2002;86:1745-50
117. Iribarren C, Haselkorn T, Tekawa IS, Friedman GD. Cohort study of thyroid cancer in a San Francisco Bay area population. Int J Cancer. 2001;93:745-50.

118. Pendergrast WJ, Milmore BK, Marcus SC. Thyroid cancer and thyrotoxicosis in the United States: their relation to endemic goiter. J Chronic Dis. 1961;13:22-38.

119. Clements FW. The relationship of thyrotoxicosis and carcinoma of the thyroid to endemic goitre. Med J Aust. 1954;2:894-7.

120. Brito JP, Yarur AJ, Prokop LJ, Mclver B, Murad MH, Montori VM. Prevalence of thyroid cancer in multinodular goiter versus single nodule: a systematic review and meta-analysis. Thyroid. 2013;23:449-55.

121. Kolonel LN, Hankin JH, Wilkens LR, Fukunaga FH, Hinds MW. An epidemiologic study of thyroid cancer in Hawaii. Cancer Causes Control. 1990; 1:223-34

122. Truong T, Baron-Dubourdieu D, Rougier Y, Guenel P. Role of dietary iodine and cruciferous vegetables in thyroid cancer: a countrywide case-control study in New Caledonia. Cancer Causes Control. 2010;21:1183-92.

123. Clero E, Doyon F, Chungue V, Rachedi F, Boissin JL, Sebbag J, et al. Dietary iodine and thyroid cancer risk in French Polynesia: a case-control study. Thyroid. 2012;22:422-9.

124. Panityakul T, Bumrungsup C, Knapp G. On estimating residual heterogeneity in random-effects meta-regression: a comparative study. J Stat Theory Appl. 2013;12:253-65.

125. R Core Team. R: A language and environment for statistical computing. $R$ Foundation for Statistical Computing, Vienna, Austria. Available at: http://www.R-project.org/. 2014.

126. Viechtbauer W. Conducting meta-analyses in $\mathrm{R}$ with the metafor package. J Stat Softw. 2010;36:1-48.

127. Lumley T. rmeta: Meta-analysis. R package version 2.16. Available at: http://CRAN.R-project.org/package=rmeta. 2012.

128. Liu ZT, Lin AH. Dietary factors and thyroid cancer risk: a meta-analysis of observational studies. Nutr Cancer. 2014;66:1165-78.

129. Bosetti C, Kolonel L, Negri E, Ron E, Franceschi S, Dal Maso L, et al. A pooled analysis of case-control studies of thyroid cancer. VI. Fish and shellfish consumption. Cancer Causes Control. 2001;12:375-82.

130. Perrine CG, Sullivan KM, Flores R, Caldwell KL, Grummer-Strawn LM. Intakes of dairy products and dietary supplements are positively associated with iodine status among US Children. J Nutr. 2013;143:1155-60.

131. Zimmermann MB. Symposium on 'Geographical and geological influences on nutrition': lodine deficiency in industrialised countries. Proc Nutr Soc. 2010;69:133-43.

132. Haldimann M, Alt A, Blanc A, Blondeau K. lodine content of food groups. J Food Compos Anal. 2005;18:461-71.

133. Brauer VF, Brauer WH, Fuhrer D, Paschke R. lodine nutrition, nodular thyroid disease, and urinary iodine excretion in a German university study population. Thyroid. 2005;15:364-70.

134. Galanti MR, Hansson L, Bergstrom R, Wolk A, Hjartaker A, Lund E, et al. Diet and the risk of papillary and follicular thyroid carcinoma: a population-based case-control study in Sweden and Norway. Cancer Causes Control. 1997;8:205-14

135. Franceschi S, Levi F, Negri E, Fassina A, La Vecchia C. Diet and thyroid cancer: a pooled analysis of four European case-control studies. Int J Cancer. 1991;48:395-8.

136. Mack WJ, Preston-Martin S, Dal Maso L, Galanti R, Xiang M, Franceschi S, et al. A pooled analysis of case-control studies of thyroid cancer: cigarette smoking and consumption of alcohol, coffee, and tea. Cancer Causes Control. 2003;14:773-85.

137. Bandurska-Stankiewicz E, Aksamit-Bialoszewska E, Rutkowska J, Stankiewicz A, Shafie D. The effect of nutritional habits and addictions on the incidence of thyroid carcinoma in the Olsztyn province of Poland. Endokrynol Pol. 2011;62:145-50.

138. Park Y, Leitzmann MF, Subar AF, Hollenbeck A, Schatzkin A. Dairy food, calcium, and risk of cancer in the NIH-AARP Diet and Health Study. Arch Intern Med. 2009;169:391-401.

139. Schneider AB, Shore-Freedman E, Weinstein RA. Radiation-induced thyroid and other head and neck tumors: occurrence of multiple tumors and analysis of risk factors. J Clin Endocrinol Metab. 1986;63:107-12.

140. Ron E, Lubin JH, Shore RE, Mabuchi K, Modan B, Pottern LM, et al. Thyroid cancer after exposure to external radiation: a pooled analysis of seven studies. Radiat Res. 1995;141:259-77.

141. Williams D. Twenty years' experience with post-Chernobyl thyroid cancer. Best Pract Res Clin Endocrinol Metab. 2008;22:1061-73. 
142. Robbins J, Dunn JT, Bouville A, Kravchenko VI, Lubin J, Petrenko S, et al. lodine nutrition and the risk from radioactive iodine: a workshop report in the chernobyl long-term follow-up study. Thyroid. 2001;11:487-91.

143. Shakhtarin W, Tsyb AF, Stepanenko VF, Orlov MY, Kopecky KJ, Davis S. lodine deficiency, radiation dose, and the risk of thyroid cancer among children and adolescents in the Bryansk region of Russia following the Chernobyl power station accident. Int J Epidemiol. 2003;32:584-91.

144. Cardis E, Kesminiene A, Ivanov V, Malakhova I, Shibata Y, Khrouch V, et a Risk of thyroid cancer after exposure to 1311 in childhood. J Natl Cancer Inst. 2005;97:724-32.

145. Tronko MD, Howe GR, Bogdanova TI, Bouville AC, Epstein OV, Brill AB, et al. A cohort study of thyroid cancer and other thyroid diseases after the chornobyl accident: Thyroid cancer in Ukraine detected during first screening. J Natl Cancer I. 2006;98:897-903.

146. Zablotska LB, Ron E, Rozhko AV, Hatch M, Polyanskaya ON, Brenner AV, et al. Thyroid cancer risk in Belarus among children and adolescents exposed to radioiodine after the Chornobyl accident. Br J Cancer. 2011;104:181-7.

147. Hatch M, Polyanskaya O, McConnell R, Gong ZH, Drozdovitch V, Rozhko A, et al. Urinary lodine and goiter prevalence in Belarus: experience of the Belarus-American cohort study of thyroid cancer and other thyroid diseases following the Chornobyl nuclear accident. Thyroid. 2011;21:429-37.

148. Heitz P, Moser H, Staub JJ. Thyroid cancer: a study of 573 thyroid tumors and 161 autopsy cases observed over a thirty-year period. Cancer. 1976;37:2329-37.

149. Lind P, Langsteger W, Molnar M, Gallowitsch HJ, Mikosch P, Gomez I. Epidemiology of thyroid diseases in iodine sufficiency. Thyroid. 1998;8:1179-83.

150. Huszno B, Szybinski Z, Przybylik-Mazurek E, Stachura J, Trofimiuk M, BuziakBereza $M$, et al. Influence of iodine deficiency and iodine prophylaxis on thyroid cancer histotypes and incidence in endemic goiter area. J Endocrinol Invest. 2003;26:71-6.

151. Pingitore R. Rilievi morfologici autoptici su 111 tiroidi clinicamente normali in un'area italiana senza edemia gozzigena. Pathologica. 1982;74:545-52.

152. Arellano L, Ibarra A. Occult carcinoma of the thyroid gland. Pathol Res Pract. 1984;179:88-91.

153. Sobrinho-Simoes MA, Sambade MC, Goncalves V. Latent thyroid-carcinoma at autopsy - study from Oporto, Portugal. Cancer. 1979;43:1702-6.

154. Siegal A, Modan M. Latent Carcinoma of Thyroid in Israel - a Study of 260 Autopsies. Israel J Med Sci. 1981;17:249-53.

155. Lang W, Borrusch $H$, Bauer L. Occult carcinomas of the thyroid. Evaluation of 1,020 sequential autopsies. Am J Clin Pathol. 1988;90:72-6.

156. Martinez-Tello FJ, Martinez-Cabruja R, Fernandez-Martin J, Lasso-Oria C, Ballestin-Carcavilla C. Occult carcinoma of the thyroid. A systematic autopsy study from Spain of two series performed with two different methods. Cancer. 1993;71:4022-9.

157. Furmanchuk AW, Roussak N, Ruchti C. Occult thyroid carcinomas in the region of Minsk, Belarus. An autopsy study of 215 patients. Histopathology. 1993:23:319-25.

158. Avetisian IL, Petrova GV. Latent thyroid pathology in residents of Kiev, Ukraine. J Environ Pathol Toxicol Oncol. 1996;15:239-43.

159. Solares CA, Penalonzo MA, Xu M, Orellana E. Occult papillary thyroid carcinoma in postmortem species: prevalence at autopsy. Am J Otolaryng. 2005;26:87-90

160. Bondeson L, Ljungberg O. Occult thyroid carcinoma at autopsy in Malmo, Sweden. Cancer. 1981;47:319-23.

161. Komorowski RA, Hanson GA. Occult thyroid pathology in the young-adult an autopsy study of 138 patients without clinical thyroid-disease. Hum Pathol. 1988;19:689-96.

162. Bisi H, Fernandes VS, de Camargo RY, Koch L, Abdo AH, de Brito T. The prevalence of unsuspected thyroid pathology in 300 sequential autopsies, with special reference to the incidental carcinoma. Cancer. 1989;64:1888-93.

163. Ottino A, Pianzola HM, Castelletto RH. Occult papillary thyroid-carcinoma at autopsy in La-Plata, Argentina. Cancer. 1989;64:547-51.

164. Thorvaldsson SE, Tulinius H, Bjornsson J, Bjarnason O. Latent thyroidcarcinoma in Iceland at autopsy. Pathol Res Pract. 1992;188:747-50.

165. Chong PY. Thyroid carcinomas in Singapore autopsies. Pathology. 1994;26:20-2.

166. Mitselou A, Vougiouklakis T, Peschos D, Dallas P, Agnantis NJ. Occult thyroid carcinoma. A study of 160 autopsy cases. The first report for the region of Epirus-Greece. Anticancer Res. 2002;22:427-32.

167. Tanriover O, Comunoglu N, Eren B, Comunoglu C, Turkmen N, Dogan M, et al. Occult papillary thyroid carcinoma: prevalence at autopsy in Turkish people. Eur J Cancer Prev. 2011;20:308-12.
168. Hazard JB, Kaufman N. A survey of thyroid glands obtained at autopsy in a so-called goiter area. Am J Clin Pathol. 1952;22:860-5.

169. Mortensen JD, Woolner LB, Bennett WA. Gross and microscopic findings in clinically normal thyroid glands. J Clin Endocrinol Metab. 1955;15:1270-80.

170. Hull OH. Critical analysis of two hundred twenty-one thyroid glands; study of thyroid glands obtained at necropsy in Colorado. AMA Arch Pathol. 1955;59:291-311

171. Brierre Jr JT, Dickson LG. Clinically unsuspected thyroid disease. GP. 1964;30:94-8.

172. Silverberg SG, Vidone RA. Carcinoma of thyroid in surgical and postmortem material - analysis of 300 cases at autopsy and literature review. Ann Surg. 1966;164:291-9.

173. Farooki MA. Epidemiology and pathology of cancer of the thyroid. I. Material, methods and results. Int Surg. 1969;51:232-43.

174. Sampson RJ, Woolner LB, Bahn RC, Kurland LT. Occult thyroid carcinoma in Olmsted County, Minnesota: prevalence at autopsy compared with that in Hiroshima and Nagasaki, Japan. Cancer. 1974;34:2072-6.

175. de Matos PS, Ferreira AP, Ward LS. Prevalence of papillary microcarcinoma of the thyroid in Brazilian autopsy and surgical series. Endocr Pathol. 2006;17:165-73.

176. Fukunaga FH, Lockett LJ. Thyroid carcinoma in the Japanese in Hawaii. Arch Pathol. 1971;92:6-13.

\section{Submit your next manuscript to BioMed Central and take full advantage of:}

- Convenient online submission

- Thorough peer review

- No space constraints or color figure charges

- Immediate publication on acceptance

- Inclusion in PubMed, CAS, Scopus and Google Scholar

- Research which is freely available for redistribution 